IFN Working Paper No. 1098, 2015

\title{
Auction Performance on Wholesale Electricity Markets in the Presence of Transmission Constraints and Transmission Costs
}

Mario Blazquez de Paz 


\title{
Auction Performance on Wholesale Electricity Markets in the Presence of Transmission Constraints and Transmission Costs *
}

\author{
Mario Blazquez de Paz ${ }^{\dagger}$
}

This version: December 15, 2015

\begin{abstract}
Electricity markets are becoming more integrated around the world. However, the knowledge of the effects of different auction formats on suppliers' strategies in the presence of transmission constraints and transmission costs is still very limited. In this paper, I analyze the performance of uniform and discriminatory price auctions in the presence of transmission constraints and transmission costs. When the transmission capacity is binding, the discriminatory price auction could outperform the uniform price auction, minimizing the equilibrium price and the transmission costs. Moreover, when the transmission capacity is binding, an increase in transmission costs could be pro-competitive when the auction is discriminatory, but not when the auction is uniform.
\end{abstract}

KEYWORDS: electricity auctions, transmission constraint, transmission costs, market design.

\footnotetext{
${ }^{*}$ I am very grateful to Giacomo Calzolari and Emanuele Tarantino for comments and excellent supervision during my Ph.D. Daniel Kovenock made very useful comments on the existence of the equilibrium in the presence of transmission costs. I am also very grateful for fruitful discussions and comments from Ola Andersson, Claude Crampes, Oscar Erixson, Shon Ferguson, Pär Holmberg, Henrik Horn, Ewa Lazarczyk, Thomas-Olivier Léautier, Chloé Le Coq, Pehr-Johan Norbäck, Andy Philpott, Michele Polo, Mar Reguant, Andrew Rodes, Keith Ruddell, Thomas Tangerås, workshop participants at Toulouse School of Economics and Vaxholm (Stockholm), seminar participants at Bologna University, Research Institute of Industrial Economics (IFN), Complutense University, Salamanca University and conference participants at Mannheim Energy Conference and Industrial Organization: Theory, Empirics and Experiments in Alberobello (Italy). This research was completed within the framework of the IFN research program "The Economics of Electricity Markets". I acknowledge financial support from the Torsten Söderberg Foundation and the Swedish Energy Agency. Fredrik Andersson helped me translate parts of the paper into Swedish. Christina Loennblad helped me proofread the paper.

${ }^{\dagger}$ Research Institute of Industrial Economics. Mail: mario.blazquezdepaz@ifn.se
} 


\section{Introduction}

Electricity markets are becoming more integrated around the world. In such a context, transmission capacities and transmission tariffs play a crucial role in determining equilibrium market allocations. However, the knowledge of the effects of different auction formats on suppliers' strategies in the presence of transmission constraints and transmission costs is still very limited. In this paper, I analyze the performance of the uniform and the discriminatory price auction in the presence of transmission constraints and transmission costs.

The analysis employs a simple duopoly model similar to that in Fabra et al. (2006). In the basic set up, the two suppliers have symmetric production capacities and marginal costs, but are located in two different markets ("North" and "South") that are connected through a transmission line with a limited transmission capacity. ${ }^{1}$ The equilibrium price is the same in both markets even when the transmission line is congested. Electricity markets with this price structure are very common (e.g., Spain and France); moreover, this price structure also appears in nodal electricity markets where the transmission line is congested within a node (e.g., Italy). Each supplier faces a perfectly inelastic demand in each market that is known with certainty when suppliers submit their offer prices. Each supplier must submit a single price offer for its entire capacity. ${ }^{2}$ When the auction is discriminatory, the suppliers dispatched receive their own bid; when the auction is uniform, the suppliers dispatched receive the maximum bid accepted in the auction. The assumption of price-inelastic demand can be justified by the fact that the vast majority of consumers purchase electricity under regulated tariffs that are independent of the prices set in the wholesale market, at least in the short run. The assumption that suppliers have perfect information concerning market demand is reasonable when applied to markets where offers are "short lived", such as in Spain, where there are 24 hourly day-ahead markets each day.

Suppliers pay a monetary charge (tariff) to the network owner when using the grid. The charge is linear and it depends on how much power they inject into the grid (point of connection tariff) or transmit through the grid (transmission tariff). The majority of European countries (ENTSO-E, 2013) have point of connection tariffs. With the point of connection tariffs scheme, suppliers pay a linear tariff for the electricity injected into the grid, i.e., the one sold in their own market and the one sold in the other market. From the suppliers' point of view, a connection tariff is equivalent to an increase in generation costs. Given that electricity demand is very inelastic, an increase in generation costs is passed through to consumers that face an increase in equilibrium prices in both markets. This is in line with the pass-through literature (Marion and Muehlegger 2011; Fabra and Reguant 2014). For transmission tariffs, electricity suppliers would only pay a linear tariff for the electricity sold to the other market. Hence, similar to a trade model, firms only pay a transport cost for the goods sold in the other market. As has been shown in Blázquez (2015), transmission tariffs are better than point of connection tariffs from the consumers' perspective. Therefore, in this paper, I restrict the analysis to transmission tariffs.

\footnotetext{
1 The term "transmission capacity constraint" is used throughout this article in the electrical engineering sense: a transmission line is constrained when the flow of power is equal to the capacity of the line, as determined by engineering standards.

${ }^{2}$ Fabra et al. (2006) show that the equilibrium outcome allocation does not change when suppliers submit single price offers for their entire capacity and when they submit a set of price-quantity offers.
} 
When there are constraints on the possibility to export electricity to another market, the effective size of the market differs for the suppliers. The supplier located in the high-demand market faces a higher residual demand, while the supplier located in the low-demand market cannot sell its entire generation capacity. Therefore, the supplier located in the high-demand market has incentives to submit higher bids than the supplier located in the low-demand market (size effect). Transmission costs also introduce an asymmetry. The supplier located in the low-demand market has to sell a large part of its generation capacity into the other market and thus, it faces a high transmission cost and it has incentives to increase its bid. The transmission cost makes the supplier in the high-demand market more efficient in relative terms. In order to exploit its efficiency rent, it has incentives to submit lower bids and, for a sufficiently high transmission cost, the efficient supplier will even try to undercut the exporting supplier (cost effect). The equilibrium outcome allocation in both types of auctions is determined by the dominating effect.

When the transmission costs are low and the transmission capacity is binding, the discriminatory price auction outperforms the uniform price auction in terms of equilibrium price and transmission cost minimization; when the transmission capacity is not binding, the discriminatory price auction generates a lower equilibrium price, but the performance in terms of transmission cost minimization depends on the equilibrium played in the uniform price auction. When the transmission costs are high and the transmission capacity is binding, the equilibrium outcome allocations are the same for both types of auctions; when the transmission capacity is not binding, the discriminatory price auction generates a lower equilibrium price, but the performance in terms of transmission cost minimization depends on the equilibrium played in the uniform price auction. Hence, due to the structure of the model (transmission constraints and costs), the discriminatory price auction outperforms the uniform price auction even when the suppliers are symmetric in production capacity and production costs. This is in contrast to the previous results in the literature (Fabra et al., 2006), where the performance of both types of auctions crucially depends on the parameter assumptions.

Due to the transmission constraint, the supplier located in the high-demand market faces a large residual demand and it has incentives to increase its bid. Moreover, due to the asymmetry on demand realization, an increase in transmission costs induces different changes in suppliers' costs. The supplier located in the low-demand market faces a large increase in transmission costs and it has incentives to increase its bid to compensate for the increase in costs. The supplier located in the high-demand market faces a low increase in transmission costs and it has incentives to decrease its bid to extract the efficiency rents. The discriminatory price auction captures the changes in the incentives induced by an increase in transmission costs in a very exact way: the supplier located in the high-demand market decreases its bids to be dispatched first and the supplier located in the low-demand market increases its bid to compensate for the increase in costs. The average effect is a decrease in the equilibrium price; i.e., an increase in the transmission cost is pro-competitive. In contrast, the uniform price auction is not that flexible and an increase in transmission costs does not change suppliers' strategies and thus, the price does not change. 
Transmission constraints have been considered in different types of oligopoly models. Borenstein et al. (2000) characterize the equilibrium in an electricity network where suppliers compete in quantities as in a Cournot game. Holmberg and Philpott (2012) solve for symmetric supply function equilibria in electricity networks when demand is uncertain exante, but they do not consider any transmission costs. Escobar and Jofré (2010) analyze the effect of transmission losses, a transmission cost, on equilibrium outcome allocations, but they neglect transmission constraints. However, none of these models consider the effect that the type of auction could have by determining equilibrium outcome allocations.

Fabra et al. (2006) extend the seminal papers of Bertrand competition with capacity constrained production (Kreps and Scheinkman, 1983; Osborne and Pitchik, 1986; Deneckere and Kovenock, 1996) to include asymmetries in generation capacity and production costs. Moreover, the paper also characterizes the equilibrium when the auction is uniform and compares the performance of both types of auctions. However, the results presented in Fabra et al. (2006) the "size" and "cost" effects induced by the asymmetries in production capacity and production costs work in the same direction. In contrast, in this paper both effects work in the opposite direction and the characterization of the equilibrium and the comparative static are different that the one presented in Fabra et al. (2006). Moreover, in the annex I extend the results presented in Fabra et al. (2006) providing a general characterization of the equilibrium that does not depend on the parameter specification.

Fabra et al. (2006) analyze the performance of the uniform and the discriminatory price auctions in a context of perfect information. Holmberg and Wolak (2015) extend the analysis to a context of imperfect information and find that the uniform price auction outperforms the discriminatory price auction by generating a lower equilibrium price. However, neither of these papers analyzes the performance of both types of auctions when the suppliers face economic incentives (cost and size effect) that work in the opposite direction.

The article proceeds as follows. Section 2 describes the model. Section 3 characterizes the equilibrium and analyzes the performance of both types of auctions in the presence of transmission capacity constraints and zero transmission costs. Section 4 characterizes the equilibrium and analyzes the performance of both types of auctions in the presence of transmission capacity constraints and positive transmission costs. Section 5 concludes the paper. The extension of Fabra's paper and the proofs are located in the Appendix.

\section{The model}

Set up of the model. There exist two electricity markets, market North and market South, that are connected by a transmission line with capacity $T$. When firms transmit electricity through the grid from one market to the other, they face a symmetric linear ${ }^{3}$ transmission tariff $t$. In order to reduce transmission losses 4 the transmission tariffs in

\footnotetext{
${ }^{3}$ The transmission tariffs are linear in electricity markets. However, the model can be modified to assume convex costs. When the transmission costs are convex, the existence of the equilibrium is guaranteed by Dixon (1984).

${ }^{4}$ Electricity suppliers pay a linear tariff that depends on the location and the season/period-of-day. The locational component of the tariff component of the tariff penalizes the injection of electricity in
} 
the majority of European countries have a locational and a seasonal component $5^{5}$

There exist two duopolists with capacities $k_{n}$ and $k_{s}$, where subscript $n$ means that the supplier is located in market North and subscript $s$ means that the supplier is located in market South. The suppliers' marginal costs of production are $c_{n}$ and $c_{s}$. In this paper, I analyze the effect of transmission capacity constraints and transmission costs on the equilibrium. In order to focus on this effect, I assume that suppliers are symmetric in capacity $k_{n}=k_{s}=k>0$ and symmetric in $\operatorname{costs} c_{n}=c_{s}=c=0$. The level of demand in any period, $\theta_{n}$ in market North and $\theta_{s}$ in market South, is a random variable uniformly distributed that is independent across market ${ }^{6}$ and independent of the market price, i.e., perfectly inelastic. In particular, $\theta_{i} \in\left[\underline{\theta}_{i}, \bar{\theta}_{i}\right] \subseteq[0, k+T]$ is distributed according to some known distribution function $G\left(\theta_{i}\right), i=n, s, i \neq j$.

The capacity of the transmission line can be lower than the installed capacity in each market $T \leq k$, i.e. the transmission line could be congested for some realization of demands $\left(\theta_{s}, \theta_{n}\right)$.

Timing of the game. Having observed the realization of demands $\theta \equiv\left(\theta_{s}, \theta_{n}\right)$, each supplier simultaneously and independently submits a bid specifying the minimum price at which it is willing to supply up to its capacity, $b_{i} \leq P, i=n, s$, where $P$ denotes the "market reserve price", possibly determined by regulation.7 Let $b \equiv\left(b_{s}, b_{n}\right)$ denote a bid profile. On basis of this profile, the auctioneer calls suppliers into operation. If suppliers submit different bids, the capacity of the lower-bidding supplier is dispatched first. Without lost of generality, assume that $b_{n}<b_{s}$. If the capacity of supplier $n$ is not sufficient to satisfy total demand $\left(\theta_{s}+\theta_{n}\right)$ in the case of the transmission line not being congested, or $\left(\theta_{n}+T\right)$ in the case of the transmission line being congested 8 the higher-bidding supplier's capacity, supplier $s$, is then dispatched to serve residual demand, $\left(\theta_{s}+\theta_{n}-k\right)$ if the transmission line is not congested, or $\left(\theta_{s}-T\right)$ if the transmission line is congested. If the two suppliers submit equal bids, then supplier $i$ is ranked first with probability $\rho_{i}$, where $\rho_{n}+\rho_{s}=1, \rho_{i}=1$ if $\theta_{i}>\theta_{j}$, and $\rho_{i}=\frac{1}{2}$ if $\theta_{i}=\theta_{j}, i=n, s, i \neq j$. The tie breaking rule implemented is such that if the bids of both suppliers are equal and

points of the grid that generate high flows of electricity. The seasonal/period-of-day component of the tariff penalizes the transmission of electricity when the losses are larger. For a complete analysis of losses in Europe and a complete description of the algorithm implemented to work out power losses, consult the document "ENTSO-E ITC Transit Losses Data Report 2013".

${ }^{5}$ The locational and seasonal component implies that suppliers face asymmetric linear tariffs. However, the model can easily be modified to introduce this type of asymmetries. For a comparison of European tariff systems, check out the document "ENTSO-E Overview of transmission tariffs in Europe: Synthesis $2014 "$.

${ }^{6}$ In the majority of electricity markets, demand in one market is higher than demand in the other market. Moreover, there exists the possibility of some type of correlation between demands across markets. In this paper, I assume uniform distribution and independence of demand. However, the model can easily be modified to introduce different distributions of demand and correlation between demands across markets.

${ }^{7} \mathrm{P}$ can be interpreted as the price at which all consumers are indifferent between consuming and not consuming, or a price cap imposed by the regulatory authorities. See von der Fehr and Harbord (1993, 1998).

${ }^{8}$ When demand in market South is larger than the transmission line capacity $\theta_{s}>T$, supplier $n$ can only satisfy the demand in its own region and $T$ units of demand in region South $\left(\theta_{n}+T\right)$. Below in this section, I explain in detail the total demand and the residual demand that can be satisfied by each supplier. 
demand in market $i$ is larger than demand in region $j$, the auctioneer first dispatches the supplier located in market $i$.

The output allocated to supplier $i, i=n, s$, denoted by $q_{i}(\theta, b)$, is given by

$$
q_{i}(b ; \theta, T)= \begin{cases}\min \left\{\theta_{i}+\theta_{j}, \theta_{i}+T, k_{i}\right\} & \text { if } b_{i}<b_{j} \\ \rho_{i} \min \left\{\theta_{i}+\theta_{j}, \theta_{i}+T, k_{i}\right\}+ & \\ {\left[1-\rho_{i}\right] \max \left\{0, \theta_{i}-T, \theta_{i}+\theta_{j}-k_{j}\right\}} & \text { if } b_{i}=b_{j} \\ \max \left\{0, \theta_{i}-T, \theta_{i}+\theta_{j}-k_{j}\right\} & \text { if } b_{i}>b_{j}\end{cases}
$$

The output function has an important role in determining the equilibrium and thus, this is explained in detail. Below, I describe the construction of supplier n's output function; the one for supplier s is symmetric.

The total demand that can be satisfied by supplier $n$ when it submits the lower bid $\left(b_{n}<b_{s}\right)$ is defined by $\min \left\{\theta_{n}+\theta_{s}, \theta_{n}+T, k\right\}$. The realization of $\left(\theta_{s}, \theta_{n}\right)$ determines three different areas (left-hand panel in figure 1).

$$
\min \left\{\theta_{n}+\theta_{s}, \theta_{n}+T, k\right\}= \begin{cases}\theta_{s}+\theta_{n} & \text { if } \theta_{n} \leq k-\theta_{s} \text { and } \theta_{s}<T \\ \theta_{n}+T & \text { if } \theta_{n}<k-T \text { and } \theta_{s}>T \\ k & \text { if } \theta_{n}>k-\theta_{s} ; \theta_{s} \in[0, T] \\ & \text { or if } \theta_{n}>k-T ; \theta_{s} \in[T, k+T]\end{cases}
$$

When demand in both markets is low, supplier $n$ can satisfy total demand $\left(\theta_{s}+\theta_{n}\right)$. If the demand in market South is larger than the transmission capacity $\theta_{s}>T$, supplier $n$ cannot satisfy the demand in market South, even when it has enough generation capacity for this; therefore, the total demand that supplier $n$ can satisfy is $\left(\theta_{n}+T\right)$. Finally, if the demand is large enough, the total demand that supplier $n$ can satisfy is its own generation capacity.

The residual demand that supplier $n$ satisfies when it submits the higher bid $\left(b_{n}>b_{s}\right)$ is defined by $\max \left\{0, \theta_{n}-T, \theta_{s}+\theta_{n}-k\right\}$. The realization of $\left(\theta_{s}, \theta_{n}\right)$ determines three different cases (right-hand panel in figure 1).

$$
\max \left\{0, \theta_{n}-T, \theta_{s}+\theta_{n}-k\right\}= \begin{cases}0 & \text { if } \theta_{n}<T ; \theta_{s} \in[0, k-T] \\ & \text { or } \theta_{n}<k-\theta_{s} ; \theta_{s} \in[k-T, k] \\ \theta_{n}-T & \text { if } \theta_{n}>T \text { and } \theta_{s} \in[0, k-T] \\ \theta_{s}+\theta_{n}-k & \text { if } \theta_{n}>k-\theta_{s} ; \theta_{s} \in[k-T, T+k]\end{cases}
$$

When demand in both markets is low, supplier $s$ satisfies total demand and therefore, the residual demand that remains for supplier $n$ is zero. Due to the transmission constraint, the total demand that supplier $s$ can satisfy diminishes. As soon as the demand in market North is larger than the transmission capacity $\left(\theta_{n}>T\right)$, it cannot be satisfied by supplier $s$ and thus, some residual demand $\left(\theta_{n}-T\right)$ remains for supplier $n$. When total demand is large enough, supplier $s$ cannot satisfy total demand and some residual demand $\left(\theta_{s}+\theta_{n}-k\right)$ remains for supplier $n$.

Finally, the payments are worked out by the auctioneer. When the auctioneer runs a discriminatory price auction, the price received by a supplier for any positive quantity 
Figure 1: Output function for supplier $n .\left(k_{n}=k_{s}=60, T=40\right)$
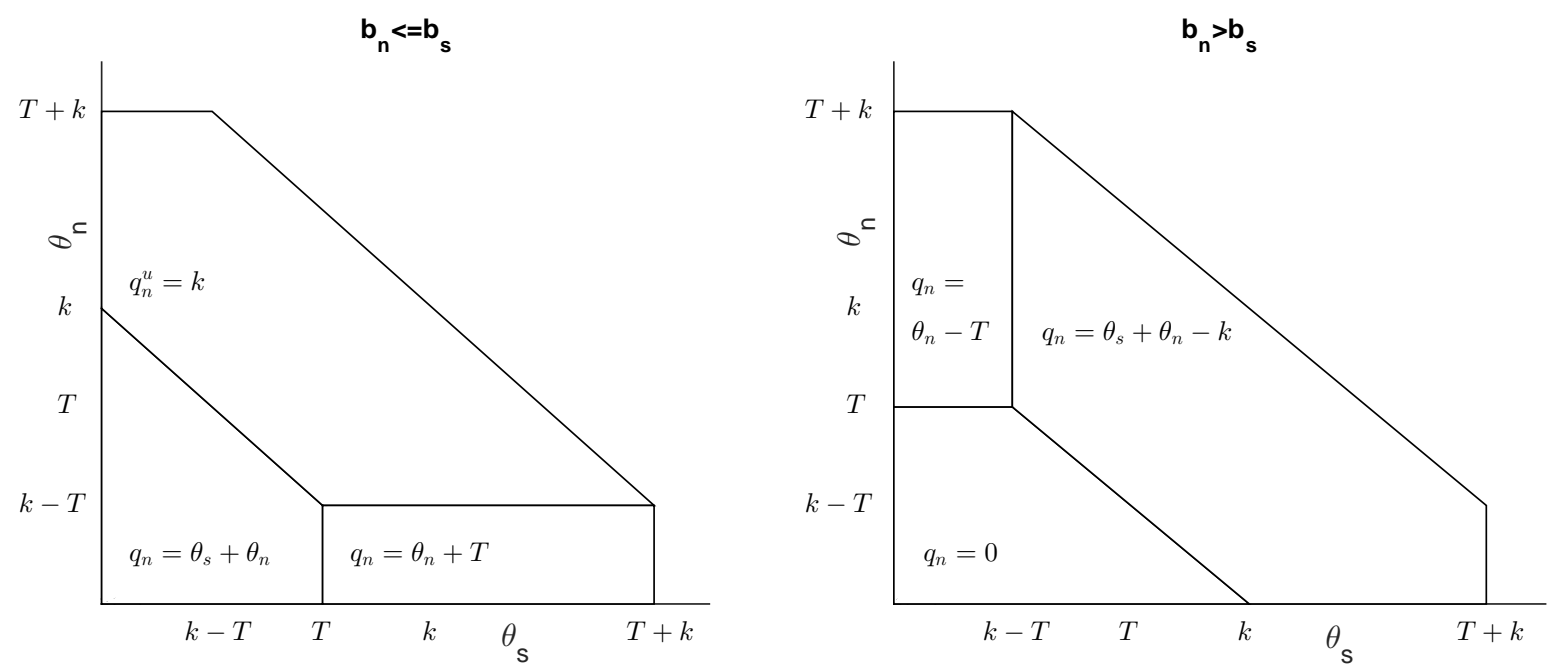

dispatched by the auctioneer is equal to its own bid. Hence, for a given realization of $\theta \equiv\left(\theta_{j}, \theta_{i}\right)$ and a bid profile $b \equiv\left(b_{j}, b_{i}\right)$, supplier $i$ 's profits can be expressed as

$$
\pi_{i}^{d}(b ; \theta, T, t)= \begin{cases}\left(b_{i}-c_{i}\right) \min \left\{\theta_{i}+\theta_{j}, \theta_{i}+T, k\right\}- & \\ \operatorname{tmax}\left\{0, \min \left\{\theta_{j}, T, k-\theta_{i}\right\}\right\} & \text { if } b_{i} \leq b_{j} \text { and } \theta_{i}>\theta_{j} \\ \left(b_{i}-c_{i}\right) \max \left\{0, \theta_{i}-T, \theta_{i}+\theta_{j}-k\right\}- & \\ \operatorname{tmax}\left\{0, \theta_{j}-k\right\} & \text { otherwise }\end{cases}
$$

The payoff function has an important role in determining the equilibrium and thus, it is explained in detail. Below, I describe the construction of supplier n's payoff function; the one for supplier s is symmetric. If $b_{n} \leq b_{s}$ and $\theta_{n} \geq \theta_{s}$, supplier n's payoff function is $\pi_{n}^{d}(b ; \theta, T)=\left(b_{n}-c_{n}\right) \min \left\{\theta_{n}+\theta_{s}, \theta_{n}+T, k\right\}$. In addition to this expression, supplier $n$ is charged a transmission cost $t$ for the power sold in market South due to the transmission costs. The transmission costs have four different possible values: $t \theta_{s}$ when the realization of demand in market North is low and the transmission line is not congested; $t T$ when the realization of demand in market North is low and the transmission line is congested; when the realization of demand in market North is high but lower than its generation capacity, the transmission costs are $t\left(k-\theta_{n}\right)$; finally, when demand in market North is larger than the generation capacity $k$, supplier $n$ cannot sell any electricity in market South and the transmission costs are zero. Hence, after adding the transmission costs, supplier n's payoff is equal to $\pi_{n}^{d}(b ; \theta, T, t)=\left(b_{n}-c_{n}\right) \min \left\{\theta_{n}+\theta_{s}, \theta_{n}+T, k\right\}-t \max \left\{0, \min \left\{\theta_{s}, T, k-\theta_{n}\right\}\right\}$ (left-hand panel, figure 2).

In the rest of the cases, supplier $n$ is dispatched last and satisfies the residual demand. Supplier n's payoff function is $\pi_{n}^{d}(b ; \theta, T, t)=\left(b_{n}-c_{n}\right) \max \left\{0, \theta_{n}-T, \theta_{s}+\theta_{n}-k\right\}$. In addition to this expression, due to the transmission costs, supplier $n$ is charged a transmission cost $t$ for the residual demand satisfied in market South. Therefore, after adding the transmission costs, supplier n's payoff is equal to $\pi_{n}^{d}(b ; \theta, T)=\left(b_{n}-\right.$ $\left.c_{n}\right) \max \left\{0, \theta_{n}-T, \theta_{s}+\theta_{n}-k\right\}-t \max \left\{0, k-\theta_{n}\right\}$ (right-hand panel, figure 2).

When the auctioneer runs a uniform price auction, the price received by a supplier for any positive quantity dispatched by the auctioneer is equal to the higher bid accepted in 
Figure 2: Profit function for supplier $n .\left(k_{n}=k_{s}=60, T=40, t>0\right)$
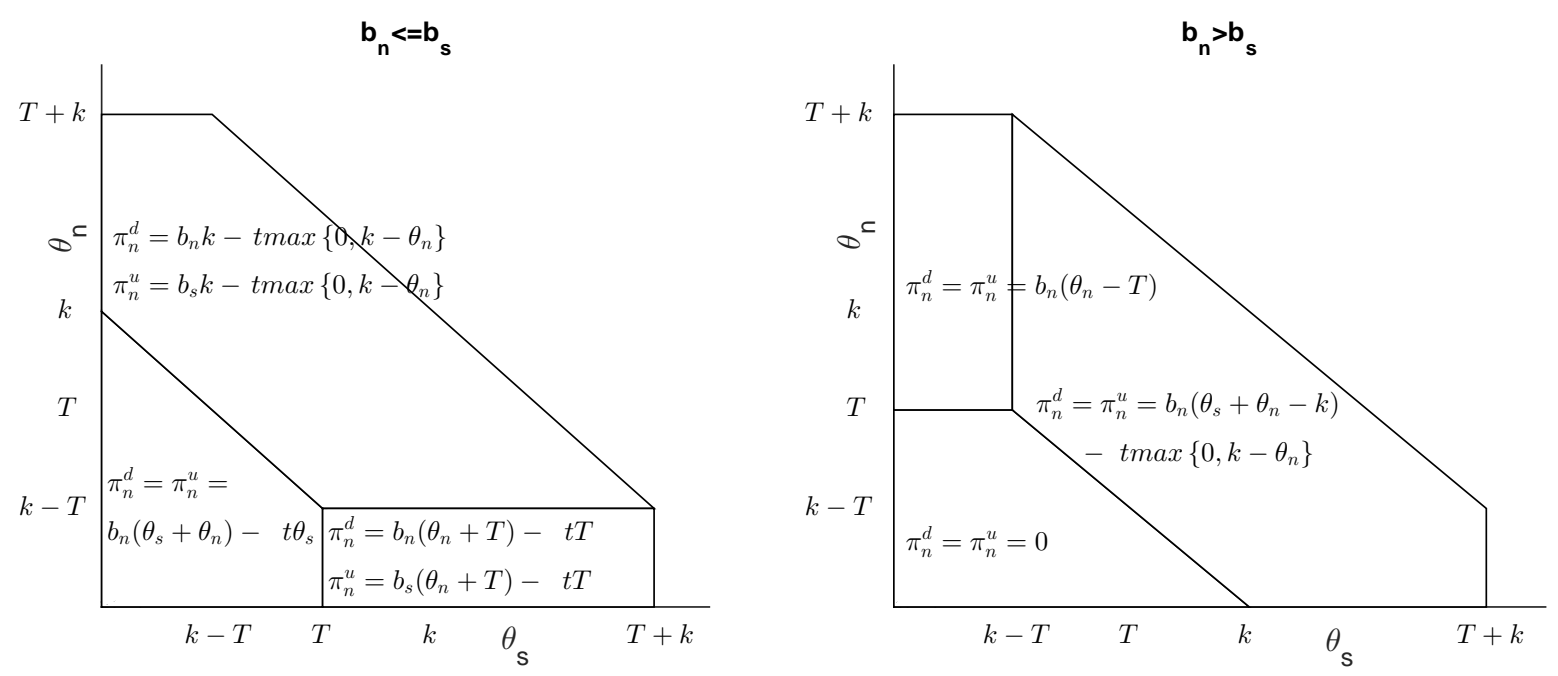

the auction. Hence, for a given realization of $\theta \equiv\left(\theta_{j}, \theta_{i}\right)$ and a bid profile $b \equiv\left(b_{j}, b_{i}\right)$, supplier $i$ 's profits can be expressed as

$\pi_{i}^{u}(b ; \theta, T, t)= \begin{cases}\left(b_{i}-c_{i}\right)\left(\theta_{i}+\theta_{j}\right)-t \theta_{j} & \text { if } b_{i} \leq b_{j} \text { and } \theta_{j} \leq T \text { and } \theta_{i}+\theta_{j} \leq k \\ \left(b_{j}-c_{i}\right) \min \left\{\theta_{i}+T, k\right\}- & \text { if } b_{i} \leq b_{j} \text { and } \theta_{j}>T \text { or } \theta_{i}+\theta_{j}>k \\ \operatorname{tmin}\left\{T, k-\theta_{i}\right\} & \\ \left(b_{i}-c_{i}\right) \max \left\{0, \theta_{i}-T, \theta_{i}+\theta_{j}-k\right\}- & \text { if } b_{i}>b_{j} \\ \operatorname{tmax}\left\{0, \theta_{j}-k\right\} & \end{cases}$

As in the discriminatory price auction, I describe the construction of supplier n's payoff function; the payoff function for supplier s is symmetric. If $b_{n} \leq b_{s}, \theta_{s} \leq T$ and $\theta_{s}+\theta_{n} \leq k$, supplier $\mathrm{n}$ submits the lower bid in the auction, the transmission line is not congested and supplier $\mathrm{n}$ has enough capacity to satisfy total demand. Therefore, supplier $\mathrm{n}$ sets the price and satisfies total demand. When $b_{n} \leq b_{s}, \theta_{s}>T$ or $\theta_{s}+\theta_{n}>k$, supplier $\mathrm{n}$ submits the lower bid in the auction, the transmission line is congested or supplier $\mathrm{n}$ does not have enough capacity to satisfy total demand, then supplier s is called into operation and sets the price. Hence, supplier n sells its generation capacity (up to the transmission line capacity) at the price set by supplier s. If supplier $\mathrm{n}$ submits the higher bid, it sets the price and satisfies the residual demand. Therefore, supplier n's profit is the same as when the auction is discriminatory.

\section{Auction performance in the presence of transmission constraints}

In the presence of transmission capacity constraints, the size of the market differs for both suppliers. The supplier located in the high-demand market faces higher residual demand and the supplier located in the low-demand market cannot sell its entire generation capacity. In this section, I characterize the equilibrium in the presence of transmission capacity constraints and zero transmission costs and I analyze the performance of both auctions based on equilibrium prices and transmission losses. I also analyze the effect of an increase in demand in each of the markets on equilibrium market outcomes. 
Lemma 1. When the realization of demands $\left(\theta_{j}, \theta_{i}\right)$ is low (area $A$ ), the equilibrium is in pure strategies for both types of auctions. When the realization of demands $\left(\theta_{j}, \theta_{i}\right)$ is intermediate (areas $A 1, B 1$ ) or high (area $B 2$ ), a multiplicity of pure strategy equilibria exists when the auction is uniform, but a pure strategies equilibrium does not exist when the auction is discriminatory (figure 3 ).

Proof. When the realization of demands $\left(\theta_{j}, \theta_{i}\right)$ is low (area $A$ ), both suppliers have enough capacity to satisfy total demand in both markets and the transmission line is not congested. Therefore, they compete fiercely to be dispatched first in the auction. Hence, the equilibrium is the typical Bertrand equilibrium where both suppliers submit bids equal to their marginal cost.

When the realization of demands $\left(\theta_{j}, \theta_{i}\right)$ is intermediate (areas $A 1, B 1$ ) or high (area $B 2)$ and the auction is uniform, a multiplicity of pure strategy equilibria exists. When the realization of demands $\left(\theta_{j}, \theta_{i}\right)$ belongs to area $A 1$, only the supplier located in the high-demand market (supplier $i$ ) can satisfy total demand. Therefore, a multiplicity of equilibria exists where supplier $i$ submits the maximum bid allowed by the auctioneer and supplier $j$ submits a bid that makes supplier $i$ indifferent between submitting the maximum bid and satisfying the residual demand or undercutting supplier $j$ and satisfying total demand. When the realization of demands $\left(\theta_{j}, \theta_{i}\right)$ belongs to areas $B 1$ or $B 2$, both suppliers face a positive residual demand. Therefore, a multiplicity of equilibria exists where one of the suppliers submits the maximum bid allowed by the auctioneer and the other submits a bid that makes undercutting unprofitable.

When the realization of demands $\left(\theta_{j}, \theta_{i}\right)$ is intermediate (areas $A 1, B 1$ ) or high (area $B 2$ ) and the auction is discriminatory, a pure strategy equilibrium does not exist. First, an equilibrium such that $b_{i}=b_{j}=c$ does not exist because at least one supplier has an incentive to increase its bid and satisfy the residual demand. Second, an equilibrium such that $b_{i}=b_{j}>c$ does not exist because at least one supplier has the incentive to undercut the other to be dispatched first. Finally, an equilibrium such that $b_{j}>b_{i}>c$ does not exist because supplier $i$ has the incentive to shade the bid submitted by supplier $j$.

When the auction is discriminatory and the realization of demands $\left(\theta_{j}, \theta_{i}\right)$ is intermediate or high, a pure strategy equilibrium does not exist. However, the model satisfies the properties ${ }^{9}$ established by Dasgupta and Maskin (1986) which guarantee that a mixed strategies equilibrium exists.

Lemma 2. In the presence of transmission constraints. In a mixed strategy equilibrium, no supplier submits a bid lower than bid $\left(\underline{b}_{i}\right)$ such that $\underline{b}_{i} \min \left\{\theta_{i}+\theta_{j}, \theta_{i}+T, k\right\}=$ $P \max \left\{0, \theta_{i}-T, \theta_{i}+\theta_{j}-k\right\}$. Moreover, the support of the mixed strategy equilibrium for both suppliers is $S=\left[\max \left\{\underline{b}_{i}, \underline{b}_{j}\right\}, P\right]$.

Proof. Each supplier can guarantee for itself the payoff $\operatorname{P\operatorname {max}}\left\{0, \theta_{i}-T, \theta_{i}+\theta_{j}-k\right\}$, because each supplier can always submit the highest bid and satisfy the residual demand. Therefore, in a mixed strategy equilibrium, no supplier submits a bid that generates a payoff equilibrium lower than $P \max \left\{0, \theta_{i}-T, \theta_{i}+\theta_{j}-k\right\}$. Hence, no supplier submits a bid

\footnotetext{
${ }^{9}$ In annex one, proposition one, I prove that the model satisfies the properties established by Dasgupta and Maskin which guarantee that a mixed strategy equilibrium exists.
} 
Figure 3: Equilibrium areas. $\left(k_{i}=k_{j}=k=60, c=0, T=40, t=0\right)$

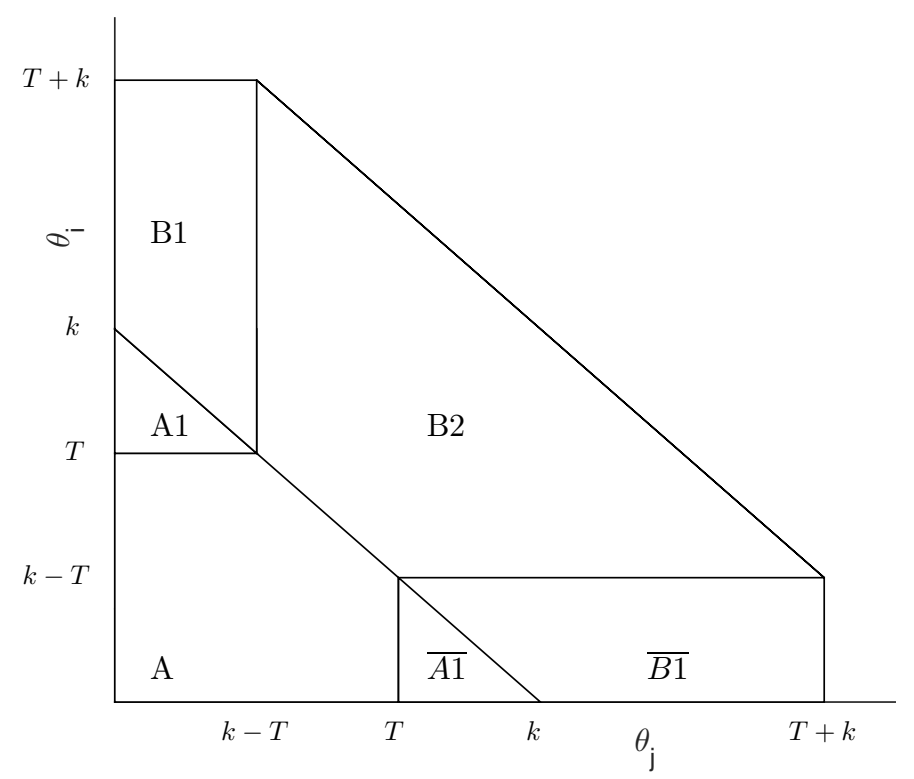

lower than $\underline{b}_{i}$, where $\underline{b}_{i}$ solves $\underline{b}_{i} \min \left\{\theta_{i}+\theta_{j}, \theta_{i}+T, k\right\}=\operatorname{P\operatorname {max}}\left\{0, \theta_{i}-T, \theta_{i}+\theta_{j}-k\right\}$.

No supplier can rationalize to submit a bid lower than $\underline{b}_{i}, i=n, s$. In the case when $\underline{b}_{i}=\underline{b}_{j}$, the mixed strategy equilibrium and the support are symmetric. In the case when $\underline{b}_{i}<\underline{b}_{j}$, supplier $i$ knows that supplier $j$ never submits a bid lower than $\underline{b}_{j}$. Therefore, in a mixed strategy equilibrium, supplier $i$ never submits a bid $b_{i}$ such that $b_{i} \in\left(\underline{b}_{i}, \underline{b}_{j}\right)$, because supplier $i$ can increase its expected payoff choosing a bid $b_{i}$ such that $b_{i} \in\left[\underline{b}_{j}, P\right]$. Hence, the equilibrium strategy support for both suppliers is $S=\left[\max \left\{\underline{b}_{i}, \underline{b}_{j}\right\}, P\right]$

Using Lemmas one and two, I characterize the equilibrium.

Proposition 1. In the presence of transmission constraints, the characterization of the equilibrium falls into one of the next two categories.

i Low demand (area $A$ ). The equilibrium strategy pair is in pure strategies for both types of auctions.

ii Intermediate demand (areas $A 1, B 1$ ) and high demand (area $B 2$ ). The equilibrium strategy pair is in pure strategies for the uniform price auction and in mixed strategies for the discriminatory price auction.

When the realization of demands $\left(\theta_{j}, \theta_{i}\right)$ is low (area $A$ ), both suppliers have enough capacity to satisfy total demand in both markets and the transmission line is not congested. Therefore, the equilibrium is the typical Bertrand equilibrium where both suppliers submit bids equal to their marginal cost. Hence, each supplier satisfies the demand in its own market and no electricity flows through the grid.

When the realization of demands $\left(\theta_{j}, \theta_{i}\right)$ is intermediate (area $A 1$ ), due to the transmission constraint, only the supplier located in the high-demand market can satisfy total 
demand. When the auction is uniform, multiplicity of equilibria exist where the supplier located in the high-demand market (supplier $i$ ) submits the maximum bid allowed by the auctioneer and the supplier located in the low-demand market (supplier $j$ ) submits a bid that makes supplier $i$ indifferent between submitting the maximum bid and satisfying the residual demand or undercutting supplier $j$ and satisfying total demand. Therefore, the equilibrium price in both markets is the maximum price allowed by the auctioneer and electricity flows from the low-demand market to the high-demand market, i.e., the electricity flow is maximized. In contrast, when the auction is discriminatory, the equilibrium price is lower than the maximum bid allowed by the auctioneer and electricity flows from the high-demand market to the low-demand market with a positive probability, i.e., the electricity flow is lower than in the uniform price auction. Hence, the discriminatory price auction performs better than the uniform price auction in terms of equilibrium price and electricity flow minimization.

When the realization of demands $\left(\theta_{j}, \theta_{i}\right)$ is intermediate (area $B 1$ ) or high (area $B 2$ ), due to the transmission or the generation constraint, both suppliers face a positive residual demand. When the auction is uniform, a multiplicity of equilibria exists where one supplier submits the maximum bid allowed by the auctioneer and the other supplier submits a bid that makes undercutting unprofitable. Therefore, the equilibrium price in both markets is the maximum price allowed by the auctioneer. Electricity flows from one market to the other, depending on the equilibrium played by the suppliers. In contrast, when the auction is discriminatory, the equilibrium price is lower than the maximum bid allowed by the auctioneer and electricity flows in expectation from the low-demand market to the high-demand market. Hence, the uniform price auction performs worse than the discriminatory price auction in terms of equilibrium price, but the performance in terms of electricity flow minimization depends on the equilibrium played in the uniform price auction.

In the rest of this section, I analyze the effect of an increase in the realization of the demand on equilibrium market outcomes.

Corollary 1. The effects of an increase in the realization of the demand in the highdemand market when the realization of demands $\left(\theta_{j}, \theta_{i}\right)$ belongs to areas $A, A 1$ and $B 1$ can be summarized as follow 10

- When the auction is uniform, an increase in the realization of demand in the highdemand market does not change the equilibrium price and increases the profit of the firm dispatched last in the auction.

- When the auction is discriminatory, an increase in the realization of demand in the high-demand market increases the lower bound of the support $\left(\underline{b}_{j}, \underline{b}_{i}\right)$, the expected bids $\left(E_{j}(b), E_{i}(b)\right)$ and the expected profits $\left(\bar{\pi}_{j}, \bar{\pi}_{i}\right)$ of both suppliers. Figure 4 summarizes the effect of an increase in demand (from area $A$ to area $B 1$ ) in the high-demand market (market North, $\theta_{n}$ ) when the demand in market South remains fixed and equal to $\theta_{s}=5$.

\footnotetext{
${ }^{10}$ The effect of an increase in demand in the high-demand market depends crucially on the realization of demands $\left(\theta_{j}, \theta_{i}\right)$. To make the corollary easier to follow, I restrict the analysis to areas $A, A 1$ and $B 1$. However, in the appendix, I present a complete analysis for the rest of the areas $(B 2)$. I follow the same approach in all corollaries: I restrict the analysis to some relevant areas in the corollaries and I complete the analysis in the annex.
} 
Figure 4: Increase $\theta_{n} .\left(\theta_{s}=5, k_{n}=k_{s}=k=60, c=0, T=40, t=0\right)$
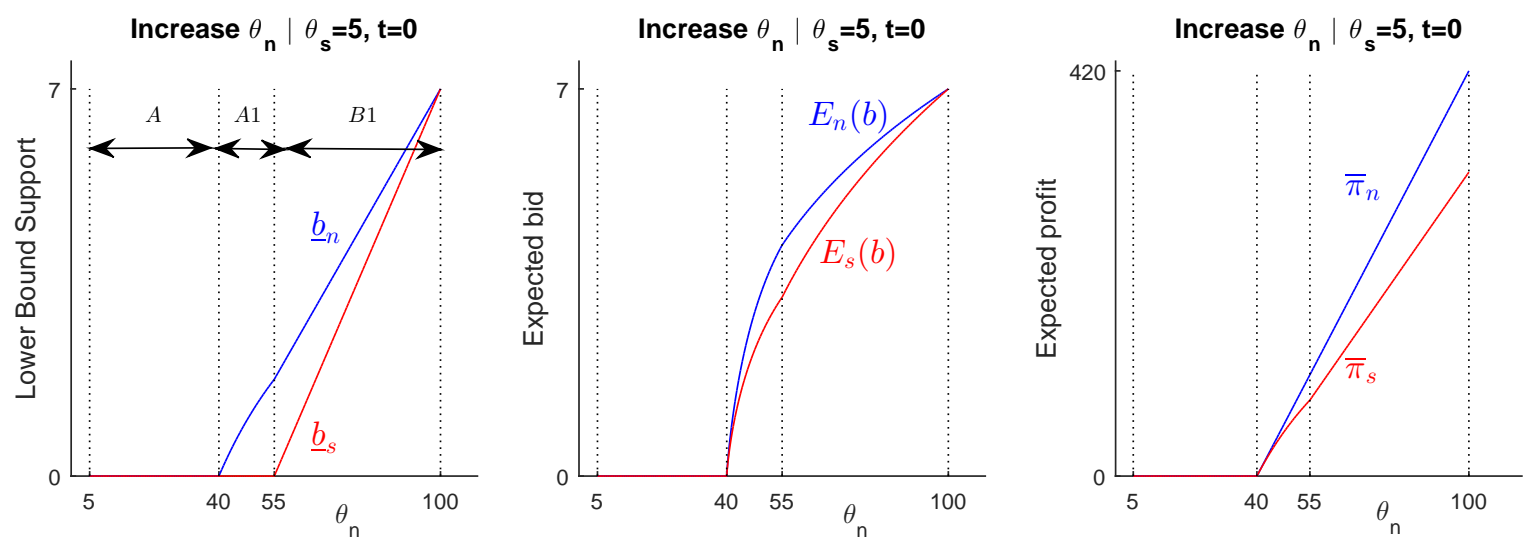

When the realization of demands $\left(\theta_{j}, \theta_{i}\right)$ belongs to area $A$, both suppliers can satisfy total demand and the equilibrium pair strategies is in pure strategies where both suppliers submit a bid equal to their marginal cost. Therefore, an increase in the realization of demand in the high-demand market does not change the equilibrium outcome. However, when the transmission or the generation capacity is binding (areas $A 1$ or $B 1$ ), at least one of the suppliers faces a positive residual demand and the equilibrium pair strategies differ for both types of auctions. Hence, an increase in demand induces different changes in outcome allocations depending on the type of auction.

When the auction is uniform, as soon as one supplier faces a positive residual demand, it has incentives to submit the maximum bid allowed by the auctioneer and the equilibrium price in both markets is high. Therefore, an increase in the realization of the demand in the high-demand market does not modify the equilibrium price. An increase in the realization of demand in the high-demand market increases the residual demand and so does the profit of the supplier dispatched last in the auction.

When the auction is discriminatory, an increase in the realization of demand in the high-demand market increases the residual demand for both suppliers and according to lemma two, the lower bound of the support increases (left-hand panel, figure 4). Due to the increase in the lower bound of the support, both suppliers randomize submitting larger bids and the expected equilibrium bids increase (central panel, figure 4). Finally, due to the increase in the residual demand and the expected bids, there is an increase in the expected profits (right-hand panel, figure 4).

Corollary 2. The effects of an increase in the realization of the demand in the lowdemand market when the realization of demands $\left(\theta_{j}, \theta_{i}\right)$ belongs to areas $B 1$ and $B 2$ can be summarized as follow.

- When the auction is uniform, an increase in the realization of demand in the lowdemand market does not change the equilibrium price and increases the profit of the firm dispatched last in the auction.

- When the auction is discriminatory and the transmission capacity is binding (area $B 1$ ), an increase in the realization of the demand in the low-demand market increases 
Figure 5: Increase $\theta_{s} .\left(\theta_{n}=60, k_{n}=k_{s}=k=60, c=0, T=40, t=0\right)$
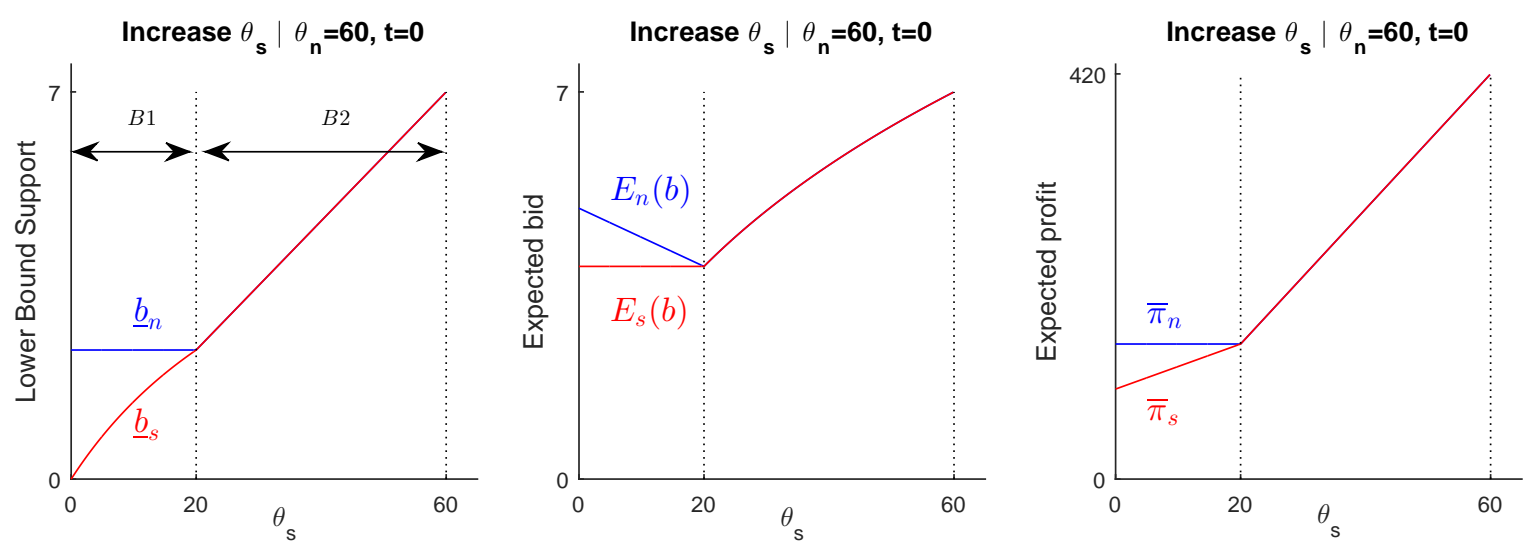

the lower bound of the support of the supplier located in the low-demand market $\left(\underline{b}_{j}\right)$ and does not change the lower bound of the support of the supplier located in the high-demand market $\left(\underline{b}_{i}\right)$; the expected bid of the supplier located in the low-demand market $\left(E_{j}(b)\right)$ does not change and the expected bid of the supplier located in the high-demand market $\left(E_{i}(b)\right)$ decreases; finally, the expected profit of the supplier located in the low-demand market $\left(\bar{\pi}_{j}\right)$ increases and the expected profit of the supplier located in the high-demand market $\left(\bar{\pi}_{i}\right)$ does not change.

- When the auction is discriminatory and the generation capacity is binding (area $B 2$ ), an increase in the realization of the demand in the low-demand market increases the lower bound of the support $\left(\underline{b}_{j}, \underline{b}_{i}\right)$, the expected bids $\left(E_{j}(b), E_{i}(b)\right)$ and the expected profits $\left(\bar{\pi}_{j}, \bar{\pi}_{i}\right)$ of both suppliers. Figure 5 summarizes the effect of an increase in demand (from area $B 1$ to area $B 2$ ) in the low-demand market (market South, $\theta_{s}$ ) when the demand in market North remains fixed and equal to $\theta_{n}=60$.

When the auction is uniform, the same logic that I have presented in corollary one applies and an increase in the demand in the low-demand market generates the same effects as an increase in the demand in the high-demand market.

When the auction is discriminatory, things are slightly more elaborated and crucially depend on the congestion of the transmission line. When the transmission capacity is not binding (area B2), both suppliers face the same residual and total demand and the lower bound of the support, the expected bids and profits are the same for both suppliers. In contrast, when the transmission capacity is binding (area B1), the supplier located in the high-demand market faces a larger residual demand and the lower bound of the support, the expected bid and the profit are larger. An increase in the demand in the low-demand market closes the gap between the total and the residual demand of both suppliers and the lower bound, the expected bid and the profit converge (area $B 1$ in figure 5). When the transmission capacity is not binding (area B2), an increase in the demand in the low-demand market increases the residual demand for both suppliers as does the lower bound, the expected bid and the profit (area B2 in figure 5). 


\section{Auction performance in the presence of transmission constraints and transmission costs}

In the presence of transmission capacity constraints, the size of the market differs for both suppliers. In the presence of transmission costs, the transmission cost differs for both suppliers depending on the realization of the demand. The supplier located in the low-demand market has to sell a large part of its generation capacity to the other market; thus, it faces a higher transmission cost than the supplier located in the high-demand market. In this section, I characterize the equilibrium in the presence of transmission capacity constraints and positive transmission costs and I analyze the performance of both auctions based on equilibrium prices and transmission losses. I also analyze the effect of an increase in the transmission cost on the main variables of the model. I conclude the section by analyzing the effect of an increase in demand in each market on equilibrium market outcomes.

Lemma 3. When the realization of demands $\left(\theta_{j}, \theta_{i}\right)$ is low (area $A$ ), the equilibrium is in pure strategies for both types of auctions. When the realization of demands $\left(\theta_{j}, \theta_{i}\right)$ is intermediate (area $A 1$ ) and the transmission costs are high, a pure strategies equilibrium exists for both types of auctions. In the rest of the cases, a multiplicity of pure strategy equilibria exists when the auction is uniform, but not when it is discriminatory (figure 6). Moreover, due to the presence of transmission costs, the pure strategy equilibria are asymmetric.

Proof. When the realization of demands $\left(\theta_{j}, \theta_{i}\right)$ is low (area $A$ ), both suppliers have enough capacity to satisfy total demand and the transmission line is not congested. Therefore, the competition for being dispatched first is fierce. Moreover, the supplier located in the high-demand market (supplier $i$ ) faces lower transmission costs. Hence, the equilibrium is the typical Bertrand equilibrium with asymmetries in "costs", 11 where the supplier located in the high-demand market undercuts the supplier located in the low-demand market to extract the efficiency rents and the electricity flows from the high-demand market to the low-demand market (the electricity flow is minimized).

When the demand belongs to area $A 1$, the transmission constraint binds for the supplier located in the low-demand market (supplier $j$ ). Therefore, only the supplier located in the high-demand market can satisfy total demand. The supplier located in that market prefers to submit a low bid and extract the efficiency rent instead of submitting a high bid and satisfy the residual demand only if the transmission cost is high enough. In such a case, the equilibrium is in pure strategies and electricity flows from the high-demand market to the low-demand market.

In the rest of the cases, a pure strategies equilibrium exists for the uniform price auction, but it does not exist for the discriminatory price auction and the proof proceeds as in lemma one

When the realization of demands $\left(\theta_{j}, \theta_{i}\right)$ is intermediate or high and the auction is discriminatory, a pure strategy equilibrium does not exist. However, the model satisfies

\footnotetext{
${ }^{11}$ It is important to emphasize that the generation costs are symmetric and equal to zero. In this model, the asymmetries in costs are due to the transmission costs.
} 
Figure 6: Equilibrium areas. $\left(k_{n}=k_{s}=k=60, c=0, T=40, t>0\right)$

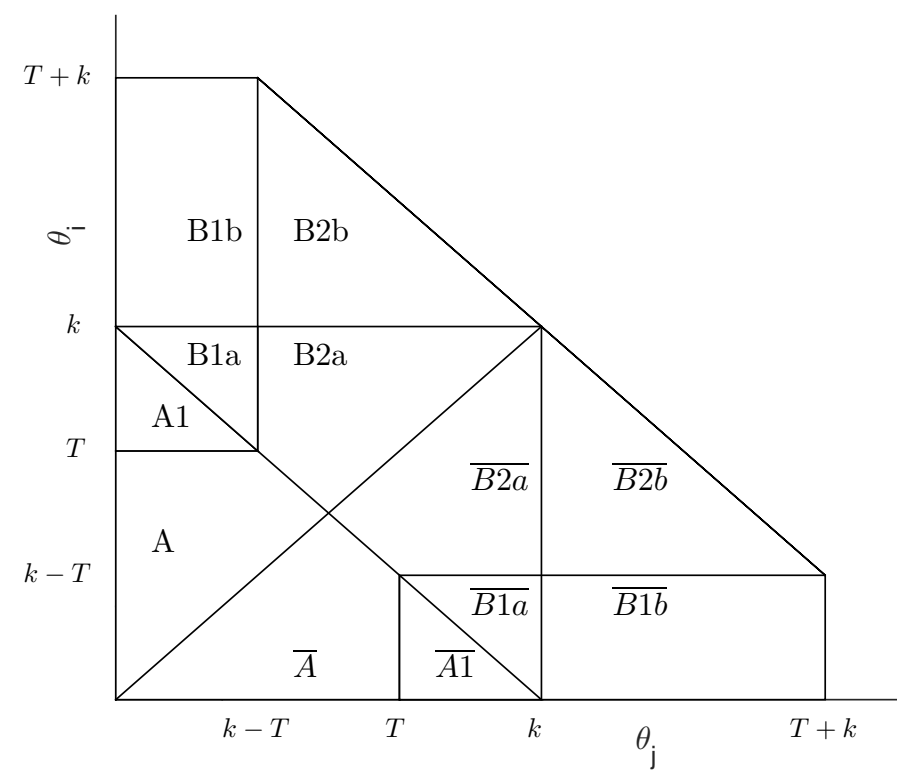

the properties established by Dasgupta and Maskin (1986) which guarantee that a mixed strategy equilibrium exists.

Lemma 4. In the presence of transmission constraints and positive transmission costs. In a mixed strategy equilibrium, no supplier submits a bid lower than bid $\left(\underline{b}_{i}\right)$ such that

$$
\begin{aligned}
& \underline{b}_{i} \min \left\{\theta_{i}+\theta_{j}, \theta_{i}+T, k\right\}-t \max \left\{0, \min \left\{\theta_{j}, T, k-\theta_{i}\right\}\right\}= \\
& P \max \left\{0, \theta_{i}-T, \theta_{i}+\theta_{j}-k\right\}-t \max \left\{0, \theta_{j}-k\right\} .
\end{aligned}
$$

Moreover, the support for the mixed strategy equilibrium for both suppliers is $S=$ $\left[\max \left\{\underline{b}_{i}, \underline{b}_{j}\right\}, P\right]$.

Proof. The proof proceeds as in lemma two.

Using lemmas three and four, I characterize the equilibrium.

Proposition 2. In the presence of transmission constraints and positive transmission costs, the characterization of the equilibrium falls into one of the next three categories.

i Low demand (area $A$ ). The equilibrium strategy pair is in pure strategies for both types of auctions.

ii Intermediate demand (area $A 1$ ). When the transmission cost is high, the equilibrium strategy pair is in pure strategies for both types of auctions. In contrast, when the transmission cost is low, the equilibrium strategy pair is in pure strategies when the auction is uniform and in mixed strategies when it is discriminatory.

iii Intermediate demand (areas $B 1 a, B 1 b$ ) and high demand (areas $B 2 a, B 2 b$ ). The equilibrium strategy pair is in pure strategies when the auction is uniform and in mixed strategies when it is discriminatory. 
When the realization of demands $\left(\theta_{j}, \theta_{i}\right)$ is low (area $A$ ), both suppliers have enough capacity to satisfy total demand in both markets and the transmission line is not congested. Moreover, the supplier located in the high-demand market faces lower transmission costs. Therefore, the equilibrium is the typical Bertrand equilibrium where the supplier located in the high-demand market submits a bid equal to the marginal cost of the supplier located in the low-demand market when it sells an extra unit of electricity into the high-demand market. Hence, the supplier located in the high-demand market satisfies the demand in both markets and the flow of electricity is minimized.

When the realization of demands $\left(\theta_{j}, \theta_{i}\right)$ is intermediate (area $A 1$ ), due to the transmission constraint, the supplier located in the high-demand market is the unique supplier that can satisfy total demand. When the transmission cost is high, the supplier located in the high-demand market faces a lower transmission cost than the one located in the lowdemand market and it is profitable to undercut it to extract the efficiency rent. In such a case, the equilibrium pair strategies are in pure strategies for both types of auctions. In contrast, when the transmission cost is low, the supplier located in the high-demand market prefers to submit a high bid and satisfy the residual demand. In such a case, a multiplicity of pure strategies equilibria exists where the supplier located in the highdemand market submits the maximum bid allowed by the auctioneer and the supplier located in the low-demand market submits a bid that makes undercutting unprofitable. When the auction is discriminatory, the equilibrium is in mixed strategies. Hence, when the transmission cost is low, the discriminatory price auction performs better in terms of equilibrium price and electricity flow minimization.

When the realization of demands $\left(\theta_{j}, \theta_{i}\right)$ is intermediate (areas $\left.B 1 a, B 1 b\right)$ or high (areas $B 2 a, B 2 b)$, the same logic that I have introduced in proposition one applies and the uniform price auction performs worse than the discriminatory price auction in terms of equilibrium price, but the performance in terms of a minimization of the electricity flow depends on the equilibrium played in the uniform price auction.

The outperformance of the discriminatory price auction in the presence of a transmission constraint and transmission costs is in contrast to the previous results in the literature where the uniform price auction can perform better than the discriminatory price auction in terms of equilibrium prices, but worse in efficiency terms. In models with an uncongested transmission line and zero transmission costs but with asymmetries in generation capacities and costs as the model presented in Fabra et al. (2006), the performance of both types of auctions crucially depends on that type of asymmetries; for some parameter specifications, the uniform price auction performs better than the discriminatory price auction in terms of efficiency, but worse for other parameter specifications. ${ }^{12}$ In contrast, in the presence of transmission constraints and costs, the discriminatory price auction outperforms the uniform price auction when the suppliers are symmetric in generation capacity and costs.

The main results presented in proposition two crucially depend on the value of the transmission cost (low or high). Due to the importance of the transmission cost for the results of the model, I analyze the effect of on increase in transmission costs on equilib-

\footnotetext{
${ }^{12}$ In the annex, I present a complete analysis of the performance of both types of auctions when the suppliers are asymmetric in generation capacities and costs.
} 
Figure 7: Increase $t$. CDF
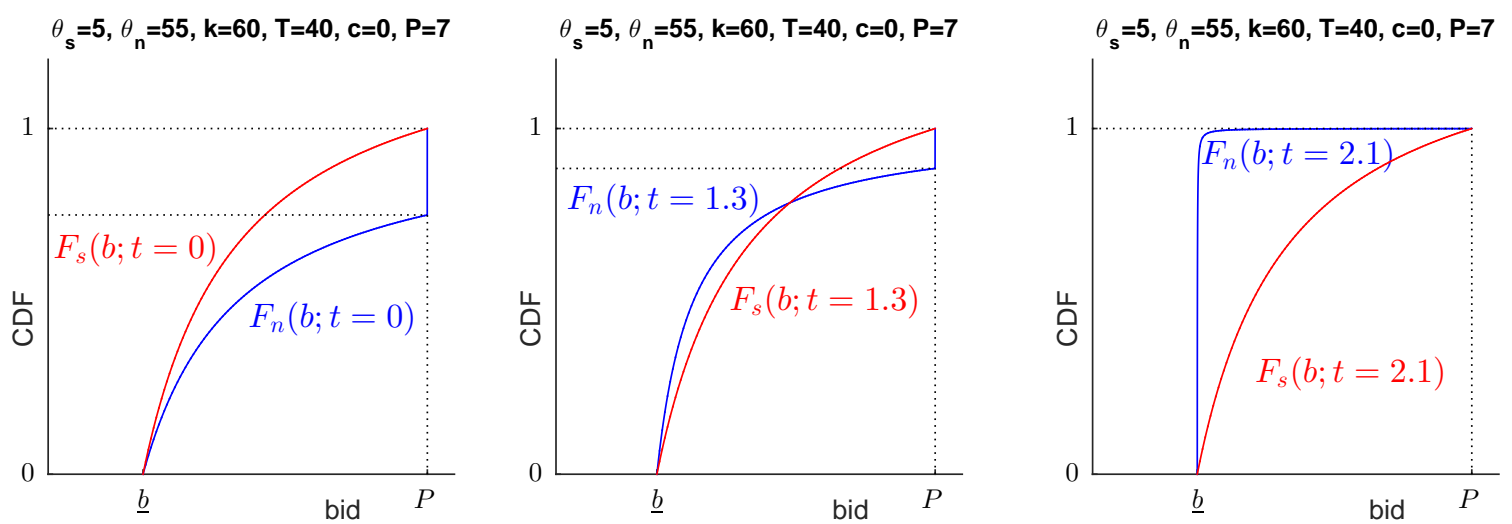

rium market outcomes.

Proposition 3. The effects of an increase in transmission costs when the realization of demands $\left(\theta_{j}, \theta_{i}\right)$ belongs to area $A 1$ can be summarized as follow.

- When the transmission costs are low, an increase in transmission costs does not modify the equilibrium price when the auction is uniform, but reduces it when the auction is discriminatory (an increase in transmission costs is pro-competitive).

- When the transmission costs are high, an increase in transmission costs increases the equilibrium price for both types of auctions (an increase in transmission costs is anti-competitive).

Due to the transmission constraint, when the realization of demands $\left(\theta_{j}, \theta_{i}\right)$ belongs to area $A 1$, the supplier located in the high-demand market (supplier $i$ ) faces a high residual demand and it has incentives to increase its bid. Moreover, due to the asymmetry on demand realization, the transmission costs are different for both suppliers. However, when the transmission cost is low, that difference is small. In such a case, the supplier located in the high-demand market prefers to submit a high bid and satisfy the residual demand. When the auction is uniform, the equilibrium is in pure strategies where the supplier located in the high-demand market submits the maximum bid allowed by the auctioneer. When the auction is discriminatory, the equilibrium is in mixed strategies where the supplier located in the high-demand market randomizes submitting higher bids than the one located in the low-demand market, i.e., the cumulative distribution function of the supplier located in the high-demand stochastically dominates that of the supplier located in the low-demand market (left-hand panel, figure 7).

When there is an increase in the transmission costs, the gap between the costs for both suppliers increases and submitting a low bid to extract the efficiency rent becomes more attractive for the supplier located in the high-demand market. The discriminatory price auction captures this effect in a very exact way: the supplier located in the highdemand market randomizes assigning a larger probability to low bids and the supplier located in the low-demand market randomizes assigning a larger probability to high bids and no cumulative distribution function stochastically dominates the other (central panel, 
Figure 8: Increase $t \mid \theta_{s}=5, \theta_{n}=55, k_{s}=k_{n}=k=60, c=0, T=40$
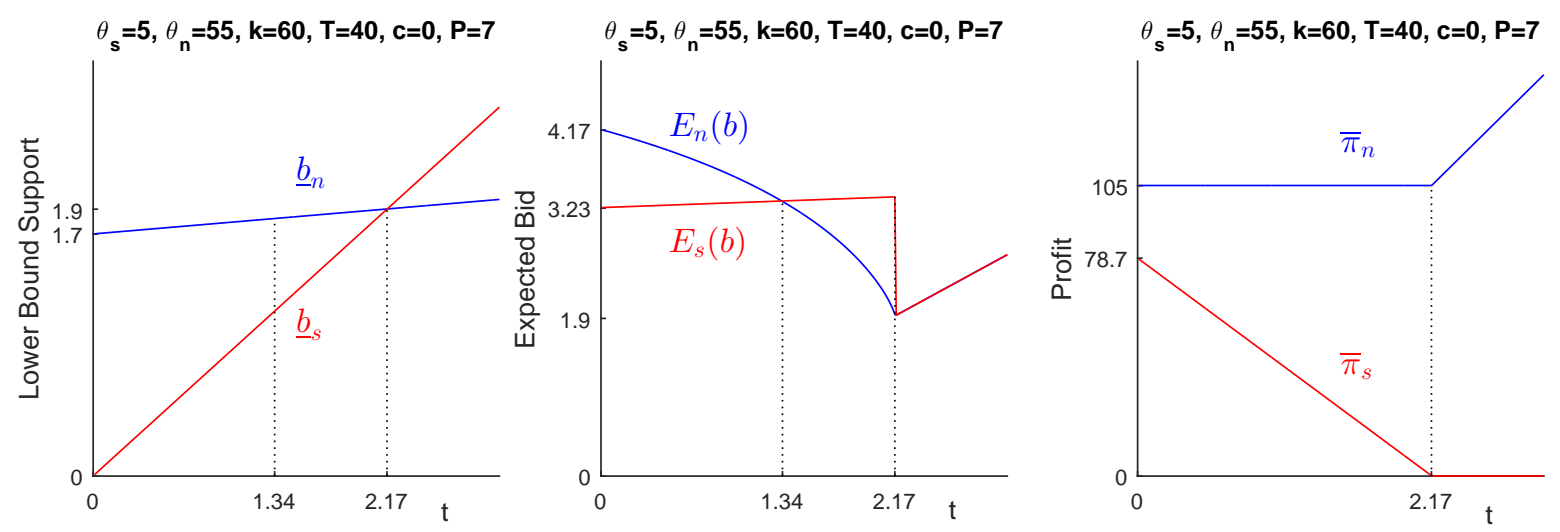

figure 7). Hence, the expected bid of the supplier located in the high-demand market decreases and the expected bid of the supplier located in the low-demand market increases (central panel, figure 8). Moreover, given that the mass of consumers is located in the high-demand market, there is an increase in aggregate consumers' welfare. In contrast, the uniform price auction is less flexible and does not capture changes in incentives and the supplier located in the high-demand market submits the maximum bid allowed by the auctioneer and satisfies the residual demand. Hence, an increase in the transmission cost is pro-competitive when the auction is discriminatory and does not modify the equilibrium prices when it is uniform.

If the transmission costs continue to increase, the supplier located in the low-demand market faces a large increase in transmission costs and the supplier located in the highdemand market has incentives to undercut it to extract the efficiency rents. Therefore, the equilibrium pair is in pure strategies for both types of auctions where both suppliers submit the same bid. Hence, when the transmission cost is sufficiently high, an increase in the transmission cost is anti-competitive.

In the rest of this section, I analyze the effect of an increase in the realization of demand on equilibrium market outcomes.

Corollary 3. The effects of an increase in the realization of the demand in the high-demand market in the presence of transmission constraints and high transmission costs when the realization of demands $\left(\theta_{j}, \theta_{i}\right)$ belongs to areas $A, A 1, B 1 a$ and $B 1 b$ can be summarized as follow.

- When the auction is uniform and the generation capacity is not binding (areas $A, A 1)$, an increase in the realization of the demand in the high-demand market increases the equilibrium price and the profit of the supplier located in the highdemand market and does not change the profit of the supplier located in the lowdemand market. When the generation capacity is binding (areas $B 1 a, B 1 b$ ), an increase in the realization of the demand in the high-demand market does not change the equilibrium price and increases the profit of the supplier dispatched last in the auction. 
Figure 9: Increase $\theta_{n} \mid \theta_{s}=5, k_{s}=k_{n}=k=60, c=0, T=40, t=2.4$
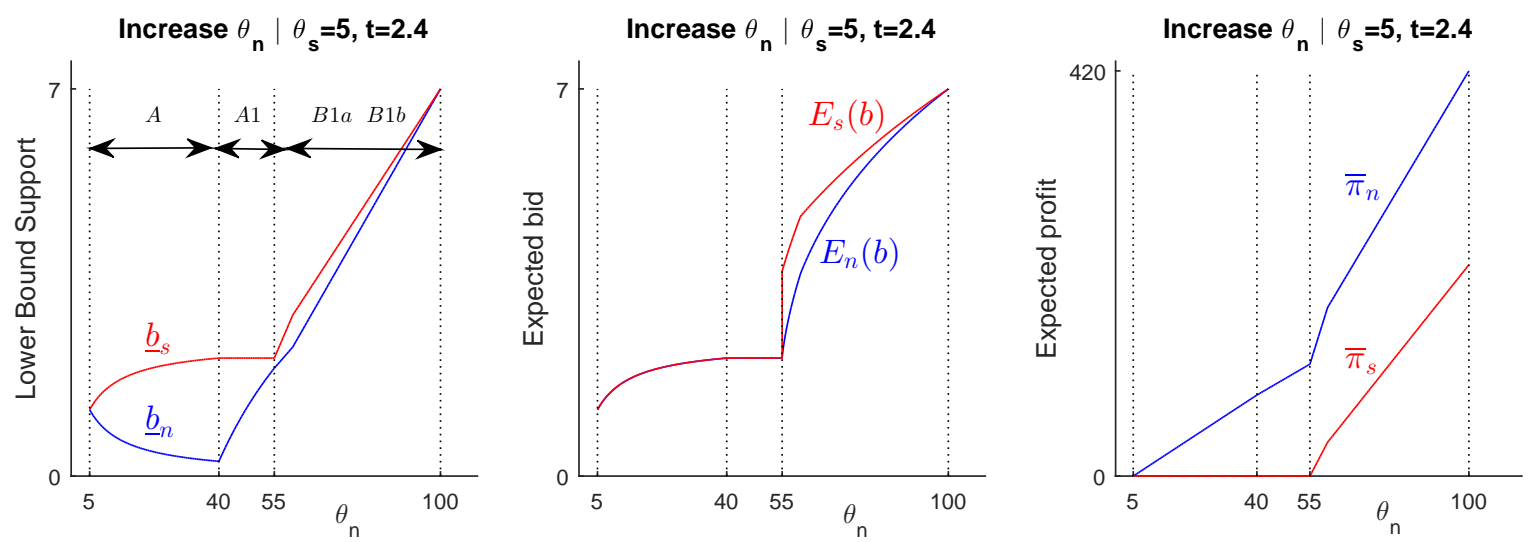

- When the auction is discriminatory and the generation capacity is not binding (areas $A, A 1)$, an increase in the realization of the demand in the high-demand market increases the equilibrium price and the profit of the supplier located in the highdemand market and does not change the profit of the supplier located in the lowdemand market. When the generation capacity is binding (areas $B 1 a$ and $B 1 b$ ), an increase in the realization of the demand in the high-demand market increases the lower bound of the support $\left(\underline{b}_{j}, \underline{b}_{i}\right)$, the expected bids $\left(E_{j}(b), E_{i}(b)\right)$ and the expected profits $\left(\bar{\pi}_{j}, \bar{\pi}_{i}\right)$ of both suppliers. Figure 9 summarizes the effect of an increase in the demand in market North (from area $A$ to area $B 1 b$ ) when the demand in market South remains fixed and equal to $\theta_{s}=5$.

When the auction is uniform and the generation capacity is not binding (areas $A$, $A 1$ ), an increase in the realization of the demand in the high-demand market induces an increase in the transmission costs for the supplier located in the low-demand market. The supplier located in the high-demand market extracts the efficiency rent rising its bid, but still undercutting the supplier located in the low-demand market. Therefore, the equilibrium price and the profit of the supplier located in the high-demand market increase; in contrast, the residual demand of the supplier located in the low-demand is nil and so are its profits. When the generation capacity is binding (areas $B 1 a, B 1 b$ ), both suppliers face a positive residual demand and the equilibrium price is the maximum bid allowed by the auctioneer. An increase in the realization of demand in the high-demand market increases the residual demand of the supplier dispatched last and thus, its profit increases.

When the auction is discriminatory and the generation capacity is not binding (areas $A, A 1)$ and the transmission cost is high, as I have proved in lemma three, the equilibrium is the same for both types of auctions. Therefore, an increase in demand in the high-demand market induces the same changes in the variables as when the auction is uniform. When the generation capacity is binding (areas $B 1 a, B 1 b$ ), an increase in the realization of demand in the high-demand market increases the residual demand for both suppliers and does not modify the transmission costs (the transmission line is at its maximum capacity); therefore, according to lemma two, the lower bound of the support increases (left-hand panel, figure 9). Due to the increase in the lower bound of the support, both suppliers randomize submitting larger bids and the expected equilibrium bids increase (central panel, figure 9). Finally, due to the increase in the residual demand and 
Figure 10: Increase $\theta_{s} \mid \theta_{n}=60, k_{s}=k_{n}=k=60, c=0, T=40, t=2.4$
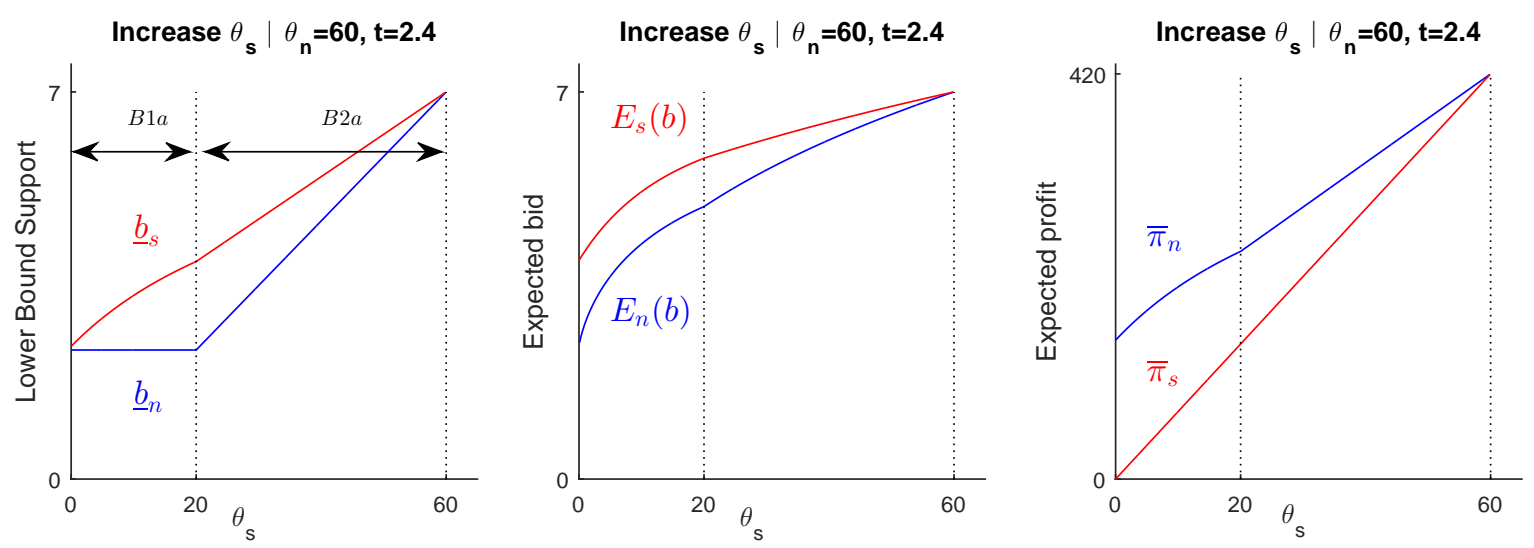

the expected bids, the expected profits increase (right-hand panel, figure 9)

Corollary 4. The effects of an increase in the realization of the demand in the low-demand market in the presence of transmission constraints and high transmission costs when the realization of demands $\left(\theta_{j}, \theta_{i}\right)$ belongs to areas $B 1 a$ and $B 2 a$ can be summarized as follow.

- When the auction is uniform, an increase in the realization of demand in the highdemand market does not change the equilibrium price and increases the profit of the supplier dispatched last in the auction.

- When the auction is discriminatory and the transmission capacity is binding (area $B 1 a$ ), an increase in the realization of the demand in the low-demand market increases the lower bound of the support of the supplier located in the low-demand market $\left(\underline{b}_{j}\right)$ and does not change the lower bound of the support of the supplier located in the high-demand market $\left(\underline{b}_{i}\right)$; the expected bids $\left(E_{j}(b), E_{i}(b)\right)$ and the expected profits $\left(\bar{\pi}_{j}, \bar{\pi}_{i}\right)$ of both suppliers increase. When the generation capacity is binding (area $B 2 a$ ), an increase in the realization of the demand in the lowdemand market increases the lower bound of the support $\left(\underline{b}_{j}, \underline{b}_{i}\right)$, the expected bids $\left(E_{j}(b), E_{i}(b)\right)$ and the expected profits $\left(\bar{\pi}_{j}, \bar{\pi}_{i}\right)$ of both suppliers. Figure 10 summarizes the effect of an increase in the demand (from area $B 1 a$ to area $B 2 a$ ) in market South $\left(\theta_{s}\right)$ when the demand in market North remains fixed and equal to $\theta_{n}=60$.

When the auction is uniform, the same logic that I have presented in previous corollaries applies and an increase in the demand in the low-demand market induces the same effects as previously presented.

When the auction is discriminatory and the transmission capacity is binding (area $B 1 a)$, an increase in the demand in the low-demand market increases the residual demand of the supplier located in that market and thus, its lower bound of the support; in contrast, the residual demand for the supplier located in the high-demand market is determined by the realization of the demand in its own market; therefore, an increase in the realization of the demand in the low-demand market does not change its residual demand and thus, the lower bound of the support does not change (left-hand panel, figure 9). Due to the increase in the lower bound of the support, the expected bids increase for both suppliers (central 
panel, figure 9p. Finally, due to the increase in the expected bid, the expected profits increase for both suppliers (right-hand panel, figure 9). When the transmission capacity is not binding (area $B 1 b$ ), an increase in the demand in the low-demand market increases the residual demand and so does the lower bound of the support and the expected bids (left-hand and central panel, figure 9); the expected profit increases due to the increase in residual demand and the expected bids (right-hand panel, figure 9).

\section{Conclusion}

Electricity markets are becoming more integrated around the world. In this paper I have analyzed the performance of uniform and discriminatory price auctions in the presence of transmission constraints and transmission costs.

When the transmission capacity is binding, the discriminatory price auction could outperform the uniform price auction, minimizing the equilibrium price and the transmission cost. Moreover, an increase in transmission costs could be pro-competitive when the auction is discriminatory, but not when the auction is uniform.

Fabra et al. (2006) analyze the performance of uniform and discriminatory price auctions when information is perfect and the suppliers are asymmetric in generation capacity and generation cost. Holmberg and Wolak (2015) extend the analysis to the case of imperfect information. However, neither of these models takes into account the effect of transmission constraints and transmission costs on equilibrium market allocations. The presence of transmission constraints and costs introduces changes in suppliers' strategies that cannot be captured with the previous models. Hence, my analysis provides useful insights for evaluating the performance of uniform and discriminatory price auctions in economic contexts similar to the one presented in this paper; i.e., where the firms face economic incentives that work in the opposite direction.

In the presence of transmission constraints and transmission costs, when the auction is uniform, a multiplicity of equilibria exists. In such a case, the uniform price auction presents the same structure as a Battle of Sexes with a continuous set of strategies. It is well know in the literature (Motta et al., 2000) that a non-equilibrium perfection approach can be used to disentangle which equilibrium is more plausible in that game. Some notable exceptions are the tracing procedure introduced by Harsanyi and Selten (1988), the robustness to strategic uncertainty method proposed by Andersson et al. (2012) and the quantal response method presented by McKelvey and Palfrey (1995). Given the importance of the equilibrium played by the suppliers to determine the minimization of transmission flows, more study is required to apply these approaches to analyze which equilibrium is selected in a uniform price auction in the presence of transmission constraints and transmission costs. 


\section{Annex 1. The effect of transmission capacity constraints}

\section{Proposition 1.}

When the auction is uniform. Using lemma one, the proof is straight forward.

When the demand is low (area $A$, figure 3): $b_{n}=b_{s}=c=0$. The equilibrium payoff is zero for both firms. No electricity flows through the grid.

When the demand is intermediate (areas $A 1$ and $B 1$, figure 3 ):

The pure strategies equilibrium is defined by

$$
b_{s} \in\left[0, \frac{P\left(\theta_{n}-T\right)}{\theta_{s}+\theta_{n}}\right] ; b_{n}=P
$$

The equilibrium price is $P$.

The payoff function is defined by

$$
\bar{\pi}_{s}=P\left(\theta_{s}+T\right) ; \bar{\pi}_{n}=P\left(\theta_{n}-T\right)
$$

The electricity flows from the low-demand market to the high-demand market.

When the demand is high (area B2, figure 3):

The pure strategies equilibrium is defined by

$$
b_{i}=P ; \quad b_{j} \in\left[0, \frac{\operatorname{Pmax}\left\{\theta_{i}-T, \theta_{j}+\theta_{i}-k\right\}}{\min \left\{\theta_{i}+T, k\right\}}\right] \forall i, j=s, n
$$

The equilibrium price is $P$.

The payoff function is defined by either

$$
\bar{\pi}_{i}=P \max \left\{\theta_{i}-T, \theta_{j}+\theta_{i}-k\right\} ; \bar{\pi}_{j}=P k \forall i, j=s, n
$$

The electricity flows from market to the other depending of which type of equilibrium emerge.

\section{When the auction is discriminatory.}

When demand is low (area $A$, figure 3): $b_{n}=b_{s}=c=0$, the equilibrium profit is zero for both firms. No electricity flows through the grid.

When demand is intermediate (areas $A 1$ and $B 1$, figure 3) or high (area $B 2$, figure 3). As I have proved in lemma one, a pure strategies equilibrium does not exist; however, the model presented in section two satisfies the properties established by Dasgupta and Maskin (1986) which guarantee that a mixed strategy equilibrium exists. In particular, the discontinuities of $\pi_{i}, \forall i, j$ are restricted to the strategies such that $b_{i}=b_{j}$. Furthermore, it is simple to confirm that by reducing its price from a position where $b_{i}=b_{j}$, 
a firm discontinuously increases its profit. Therefore, $\pi_{i}\left(b_{i}, b_{j}\right)$ is everywhere left lower semi-continuous in $b_{i}$ and hence, weakly lower semi-continuous. Obviously, $\pi_{i}\left(b_{i}, b_{j}\right)$ is bounded. Finally, $\pi_{i}\left(b_{i}, b_{j}\right)+\pi_{j}\left(b_{i}, b_{j}\right)$ is continuous because discontinuous shifts in clientele from one firm to another only occur where both firms derive the same profit per customer. Therefore, theorem five in Dasgupta and Maskin (1986) applies and hence, a mixed strategy equilibrium exists.

The existence of the equilibrium is guaranteed by Dasgupta and Maskin (1986). However, they did not provide an algorithm to work out the equilibrium. Nevertheless, using the approach proposed by Karlin (1959), Shapley (1957), Shilony (1977), Varian (1980), Deneckere and Kovenock (1986), Osborne and Pitchik (1986) and Fabra et al. (2006), the equilibrium characterization is guaranteed by construction. I use the approach proposed by this branch of the literature to work out the mixed strategy equilibrium. In particular: first, I work out the general formulas of the lower bound of the support, the cumulative distribution function, the probability distribution function, the expected equilibrium price and the expected profit; second, I work out the particular formulas associated with each single area ${ }^{13}$ in figure 3 .

Lower Bound of the Support. The lower bound of the support is defined according to lemma two.

\section{Cumulative Distribution Function.}

In the first step, the payoff function for any firm is:

$$
\begin{aligned}
\pi_{i}(b)= & b\left[F_{j}(b) \max \left\{0, \theta_{i}-T, \theta_{i}+\theta_{j}-k\right\}+\left(1-F_{j}(b)\right) \min \left\{\theta_{i}+\theta_{j}, \theta_{i}+T, k\right\}\right]= \\
= & -b F_{j}(b)\left[\min \left\{\theta_{i}+\theta_{j}, \theta_{i}+T, k\right\}-\max \left\{0, \theta_{i}-T, \theta_{i}+\theta_{j}-k\right\}\right]+ \\
& \operatorname{bmin}\left\{\theta_{i}+\theta_{j}, \theta_{i}+T, k\right\}
\end{aligned}
$$

In the second step, $\pi_{i}(b)=\bar{\pi}_{i} \forall b \in S_{i}, i=n, s$, where $S_{i}$ is the support of the mixed strategies. Then,

$$
\begin{aligned}
\bar{\pi}_{i}= & -b F_{j}(b)\left[\min \left\{\theta_{i}+\theta_{j}, \theta_{i}+T, k\right\}-\max \left\{0, \theta_{i}-T, \theta_{i}+\theta_{j}-k\right\}\right]+ \\
& b \min \left\{\theta_{i}+\theta_{j}, \theta_{i}+T, k\right\} \Rightarrow \\
F_{j}(b)= & \frac{b \min \left\{\theta_{i}+\theta_{j}, \theta_{i}+T, k\right\}-\bar{\pi}_{i}}{b\left[\min \left\{\theta_{i}+\theta_{j}, \theta_{i}+T, k\right\}-\max \left\{0, \theta_{i}-T, \theta_{i}+\theta_{j}-k\right\}\right]}
\end{aligned}
$$

The third step, at $\underline{b}, F_{i}(\underline{b})=0 \forall i=n, s$. Then,

$$
\bar{\pi}_{i}=\underline{\operatorname{bmin}}\left\{\theta_{i}+\theta_{j}, \theta_{i}+T, k\right\}
$$

In the fourth step, plugging 4 into 3 , I obtain the mixed strategies for both firms.

\footnotetext{
${ }^{13}$ The general formulas that I will introduce below fully characterize the equilibrium. However, the equilibrium presents specific characteristics in each single area. In order to fully characterize the equilibrium, I have decided to write down the formulas for each single area.
} 


$$
\begin{aligned}
F_{j}(b) & =\frac{\min \left\{\theta_{i}+\theta_{j}, \theta_{i}+T, k\right\}-\underline{\min }\left\{\theta_{i}+\theta_{j}, \theta_{i}+T, k\right\}}{b\left[\min \left\{\theta_{i}+\theta_{j}, \theta_{i}+T, k\right\}-\max \left\{0, \theta_{i}-T, \theta_{i}+\theta_{j}-k\right\}\right]}= \\
& =\frac{\min \left\{\theta_{i}+\theta_{j}, \theta_{i}+T, k\right\}}{\min \left\{\theta_{i}+\theta_{j}, \theta_{i}+T, k\right\}-\max \left\{0, \theta_{i}-T, \theta_{i}+\theta_{j}-k\right\}} \frac{b-\underline{b}}{b} \forall i=n, s
\end{aligned}
$$

For further reference:

$L_{i}(b)=\operatorname{bmin}\left\{\theta_{i}+\theta_{j}, \theta_{i}+T, k\right\}$ and

$H_{i}(b)=\operatorname{bmax}\left\{0, \theta_{i}-T, \theta_{i}+\theta_{j}-k\right\}$.

It is easy to verify that equation $F_{j}(b) \forall i, j$ is indeed a cumulative distribution function. First, in the third step, I have established that $F_{j}(\underline{b})=0$. Second, $F_{j}(b)$ is an increasing function in $b$. At $\underline{b}, L_{i}(\underline{b})=H_{i}(b)$, for any $b>\underline{b}, L_{i}(\underline{b})<H_{i}(b)$; moreover, $\frac{\partial L_{i}(b)}{\partial b}>0$, $\frac{\partial L_{i}(\underline{b})}{\partial b}=0$ and $\frac{\partial H_{i}(b)}{\partial b}>0$, therefore, $\frac{\partial\left(L_{i}(b)-L_{i}(\underline{b})\right)}{\partial b}>\frac{\partial\left(L_{i}(b)-H_{i}(b)\right)}{\partial b}$. Third, $F_{j}(b) \leq 1 \forall b \in S_{i}$. Finally, $F_{j}(b)$ is continuous in the support because $L_{i}(b)-L_{i}(\underline{b})$ and $L_{i}(b)-H_{i}(b)$ are continuous functions in the support.

\section{Probability Distribution Function.}

$$
\begin{aligned}
f_{j}(b) & =\frac{\partial F_{j}(b)}{\partial b} \\
& =\frac{\min \left\{\theta_{i}+\theta_{j}, \theta_{i}+T, k\right\} \underline{b}\left(\min \left\{\theta_{i}+\theta_{j}, \theta_{i}+T, k\right\}-\max \left\{0, \theta_{i}-T, \theta_{i}+\theta_{j}-k\right\}\right)}{b^{2}\left(\min \left\{\theta_{i}+\theta_{j}, \theta_{i}+T, k\right\}-\max \left\{0, \theta_{i}-T, \theta_{i}+\theta_{j}-k\right\}\right)^{2}} \\
& =\frac{\min \left\{\theta_{i}+\theta_{j}, \theta_{i}+T, k\right\} \underline{b}}{b^{2}\left(\min \left\{\theta_{i}+\theta_{j}, \theta_{i}+T, k\right\}-\max \left\{0, \theta_{i}-T, \theta_{i}+\theta_{j}-k\right\}\right)} \forall i=n, s
\end{aligned}
$$

Expected Equilibrium Bid.

$$
\begin{aligned}
E_{j}(b)= & \int_{\underline{b}}^{P} b f_{j}(b) \partial b \\
= & \int_{\underline{b}}^{P} \frac{\operatorname{bmin}\left\{\theta_{i}+\theta_{j}, \theta_{i}+T, k\right\} \underline{b}}{b^{2}\left(\min \left\{\theta_{i}+\theta_{j}, \theta_{i}+T, k\right\}-\max \left\{0, \theta_{i}-T, \theta_{i}+\theta_{j}-k\right\}\right)} \partial b \\
& +P\left(1-F_{j}(P)\right) \\
= & \frac{\min \left\{\theta_{i}+\theta_{j}, \theta_{i}+T, k\right\} \underline{b}}{\min \left\{\theta_{i}+\theta_{j}, \theta_{i}+T, k\right\}-\max \left\{0, \theta_{i}-T, \theta_{i}+\theta_{j}-k\right\}}[\ln (b)]_{\underline{b}}^{P} \\
& +P\left(1-F_{j}(P)\right) \forall i=n, s
\end{aligned}
$$

where $\left(1-F_{j}(P)\right)$ in equation 7 is the probability assigned by firm $j$ to the maximum price allowed by the auctioneer ${ }^{14}$

\footnotetext{
${ }^{14}$ When the transmission line is congested, the mixed strategy equilibrium is asymmetric. In such an equilibrium, the cumulative distribution function for the firm located in the low-demand market is continuous in the upper bound of the support. In contrast, the cumulative distribution function of the firm located in the high-demand region is discontinuous, which means that the firm located in the high-demand market submits the maximum bid allowed by the auctioneer with a positive probability $\left(1-F_{j}(P)\right)$. Hence, in order to work out the expected value, in addition to the integral, it is necessary to add the term $P\left(1-F_{j}(P)\right)$.
} 
Expected Profit. The expected profit is defined by equation 4 and is equal to $\bar{\pi}_{i}=$ $\underline{\min }\left\{\theta_{i}+\theta_{j}, \theta_{i}+T, k\right\}$.

In the rest of the proof, I will work out the lower bound of the support, the cumulative distribution function, the probability distribution function, the expected equilibrium price and the expected profit for the different possible realization of demands $\left(\theta_{s}, \theta_{n}\right)$.

Area $A 1$.

First, I work out the lower bound of the support on the border between areas $B 1$ and $B 2, \theta_{s}=k-T$. On the border, $\underline{b}_{n}$ solves $\underline{b}_{n} \min \left\{\theta_{n}+\theta_{s}, \theta_{n}+T, k\right\}=\operatorname{Pmax}\left\{0, \theta_{n}-T, \theta_{s}+\theta_{n}-k\right\}$, therefore $\underline{b}_{n}=\frac{P\left(\theta_{n}-T\right)}{k}$ and $\underline{b}_{s}$ solves $\underline{b}_{s} \min \left\{\theta_{n}+\theta_{s}, \theta_{s}+T, k\right\}=\operatorname{Pmax}\left\{0, \theta_{s}-T, \theta_{s}+\theta_{n}-k\right\}$, therefore $\underline{b}_{s}=\frac{P\left(\theta_{n}+\theta_{s}-k\right)}{\theta_{s}+T}$. Plugging the value of $\theta_{s}$ on the border between these areas into $\underline{b}_{s}$ formula, I obtain $\underline{b}_{s}=\frac{P\left(\theta_{n}+k-T-k\right)}{k-T+T}=\frac{P\left(\theta_{n}-T\right)}{k}=\underline{b}_{n}$. Therefore, on the border between these areas, $\underline{b}_{s}=\underline{b}_{n}=\frac{P\left(\theta_{n}-T\right)}{k}$.

In areas $A 1$ and $B 1, \underline{b}_{n}>\underline{b}_{s}$. In area $A 1$, taking partial derivatives $\frac{\partial \underline{b}_{n}}{\partial \theta_{s}}=\frac{-P\left(\theta_{n}-T\right)}{\left(\theta_{n}+\theta_{s}\right)^{2}}<$ 0 and $\frac{\partial \underline{b}_{s}}{\partial \theta_{s}}=\frac{P\left(k+T-\theta_{n}\right)}{\left(\theta_{s}+T\right)^{2}}>0$. In area $B 1$, taking partial derivatives $\frac{\partial \underline{b}_{n}}{\partial \theta_{s}}=0$ and $\frac{\partial \underline{b}_{s}}{\partial \theta_{s}}=\frac{P\left(k+T-\theta_{n}\right)}{\left(\theta_{s}+T\right)^{2}}>0$. Therefore, in areas $A 1$ and $B 1, \underline{b}_{n}>\underline{b}_{s}$. Hence, $S=\left[\max \left\{\underline{b}_{n}, \underline{b}_{s}\right\}, P\right]=\left[\underline{b}_{n}, P\right]$. In particular, in area $A 1, S=\left[\frac{P\left(\theta_{n}-T\right)}{\left(\theta_{n}+\theta_{s}\right)}, P\right]$ and in area $B 1, S=\left[\frac{P\left(\theta_{n}-T\right)}{k}, P\right]$.

Second, I work out the cumulative distribution function.

$$
\begin{gathered}
F_{s}(b)= \begin{cases}0 & \text { if } b<\underline{b} \\
\frac{\theta_{n}+\theta_{s}}{\theta_{s}+T} \frac{b-\underline{b}}{b} & \text { if } b \in(\underline{b}, P) \\
1 & \text { if } b=P\end{cases} \\
F_{n}(b)= \begin{cases}0 & \text { if } b<\underline{b} \\
\frac{\theta_{s}+T}{\theta_{s}+T} \frac{b-\underline{b}}{b} & \text { if } b \in(\underline{b}, P) \\
1 & \text { if } b=P\end{cases}
\end{gathered}
$$

Moreover,

$$
\begin{aligned}
& F_{s}(P)=\frac{\theta_{n}+\theta_{s}}{\theta_{s}+T} \frac{P-\frac{P\left(\theta_{n}-T\right)}{\theta_{n}+\theta_{s}}}{P}=1 \\
& F_{n}(P)=\frac{\theta_{s}+T}{\theta_{s}+T} \frac{P-\frac{P\left(\theta_{n}-T\right)}{\theta_{n}+\theta_{s}}}{P}=\frac{\left(\theta_{s}+T\right)}{\left(\theta_{n}+\theta_{s}\right)}<1
\end{aligned}
$$


Third, the probability distribution function is equal to:

$$
\begin{aligned}
& f_{s}(b)=\frac{\partial F_{s}(b)}{\partial b}=\frac{\theta_{n}+\theta_{s}}{\theta_{s}+T} \frac{\underline{b}}{b^{2}} \\
& f_{n}(b)=\frac{\partial F_{n}(b)}{\partial b}=\frac{\theta_{s}+T}{\theta_{s}+T} \frac{\underline{b}}{b^{2}}
\end{aligned}
$$

Fourth, the expected bid is determined by:

$$
\begin{aligned}
& E_{s}(b)=\int_{\underline{b}}^{P} b f_{s}\left(b_{s}\right) \partial b=\int_{\underline{b}}^{P} \frac{\theta_{n}+\theta_{s}}{\theta_{s}+T} \frac{b}{b} \partial b=\frac{\theta_{n}+\theta_{s}}{\theta_{s}+T} \underline{b}[\ln (b)]_{\underline{b}}^{P} \\
& E_{n}(b)=\int_{\underline{b}}^{P} b f_{n}\left(b_{n}\right) \partial b=\int_{\underline{b}}^{P} \frac{\underline{b}}{b^{2}} \partial b=\frac{\theta_{s}+T}{\theta_{s}+T} \underline{b}[\ln (b)]_{\underline{b}}^{P}+\left(1-F_{n}(P)\right) P
\end{aligned}
$$

Fifth, the expected profit is defined by equation 4 and is equal to $\bar{\pi}_{n}=\underline{b}\left(\theta_{s}+\theta_{n}\right)$ and $\bar{\pi}_{s}=\underline{b}\left(\theta_{s}+T\right)$.

Area B1.

First, the lower bound of the support is $S=\left[\frac{P\left(\theta_{n}-T\right)}{k}, P\right]$.

Second, I work out the cumulative distribution function.

$$
\begin{aligned}
& F_{s}(b)= \begin{cases}0 & \text { if } b<\underline{b} \\
\frac{k}{T+k-\theta_{n}} \frac{b-\underline{b}}{b} & \text { if } b \in(\underline{b}, P) \\
1 & \text { if } b=P\end{cases} \\
& F_{n}(b)= \begin{cases}0 & \text { if } b<\underline{b} \\
\frac{\theta_{s}+T}{T+k-\theta_{n}} \frac{b-\underline{b}}{b} & \text { if } b \in(\underline{b}, P) \\
1 & \text { if } b=P\end{cases}
\end{aligned}
$$

Moreover,

$$
\begin{aligned}
& F_{s}(P)=\frac{k}{T+k-\theta_{n}} \frac{P-\frac{P\left(\theta_{n}-T\right)}{k}}{P}=1 \\
& F_{n}(P)=\frac{\theta_{s}+T}{T+k-\theta_{n}} \frac{P-\frac{P\left(\theta_{n}-T\right)}{k}}{P}=\frac{\theta_{s}+T}{k}<1
\end{aligned}
$$

Third, the probability distribution function is equal to:

$$
\begin{aligned}
& f_{s}(b)=\frac{\partial F_{s}(b)}{\partial b}=\frac{k}{T+k-\theta_{n}} \frac{\underline{b}}{b^{2}} \\
& f_{n}(b)=\frac{\partial F_{n}(b)}{\partial b}=\frac{\theta_{s}+T}{T+k-\theta_{n}} \frac{\underline{b}}{b^{2}}
\end{aligned}
$$


Fourth, the expected bid is determined by:

$$
\begin{aligned}
E_{s}(b) & =\int_{\underline{b}}^{P} b f_{s}\left(b_{s}\right) \partial b=\int_{\underline{b}}^{P} \frac{k}{T+k-\theta_{n}} \frac{\underline{b}}{b} \partial b=\frac{k}{T+k-\theta_{n}} \underline{b}[\ln (b)]_{\underline{b}}^{P} \\
E_{n}(b) & =\int_{\underline{b}}^{P} b f_{n}\left(b_{n}\right) \partial b=\int_{\underline{b}}^{P} \frac{\theta_{s}+T}{T+k-\theta_{n}} \frac{b}{b} \partial b+\left(1-F_{n}(P)\right) P \\
& =\frac{\theta_{s}+T}{T+k-\theta_{n}} \underline{b}[\ln (b)]_{\underline{b}}^{P}+\left(1-F_{n}(P)\right) P
\end{aligned}
$$

Fifth, the expected profit is defined by equation 4 and is equal to $\bar{\pi}_{n}=\underline{b} k$ and $\bar{\pi}_{s}=\underline{b}\left(\theta_{s}+T\right)$.

Area B2.

First, the lower bound of the support is $S=\left[\max \left\{\underline{b}_{n}, \underline{b}_{s}\right\}, P\right]=\left[\frac{P\left(\theta_{s}+\theta_{n}-k\right)}{k}, P\right]$.

Second, I work out the cumulative distribution function.

$$
F_{i}(b)= \begin{cases}0 & \text { if } b<\underline{b} \\ \frac{k}{2 k-\theta_{i}-\theta_{j}} \frac{b-\underline{b}}{b} & \text { if } b \in(\underline{b}, P) \quad \forall i=s, n \\ 1 & \text { if } b=P\end{cases}
$$

Third, the probability distribution function is equal to:

$$
f_{i}(b)=\frac{\partial F_{i}(b)}{\partial b}=\frac{k}{2 k-\theta_{i}-\theta_{j}} \frac{\underline{b}}{b^{2}} \forall i=s, n
$$

Fourth, the expected bid is determined by:

$$
E_{i}(b)=\int_{\underline{b}}^{P} b f_{i}\left(b_{i}\right) \partial b=\int_{\underline{b}}^{P} \frac{k}{2 k-\theta_{n}-\theta_{s}} \frac{b}{b} \partial b=\frac{k}{2 k-\theta_{n}-\theta_{s}} \underline{b}[\ln (b)]_{\underline{b}}^{P} \quad \forall i=s, n
$$

Fifth, the expected profit is defined by equation 4 and is equal to $\bar{\pi}_{n}=\bar{\pi}_{s}=\underline{b} k$.

Corollary 1. Area $A 1$

$$
\begin{gathered}
\frac{\partial \underline{b}}{\partial \theta_{n}}=\frac{P\left(\theta_{s}+T\right)}{\left(\theta_{n}+\theta_{s}\right)^{2}}>0 \\
\frac{\partial F_{n}(P)}{\partial \theta_{n}}=\frac{-\left[\left(k+T-\theta_{n}\right)-\left(\theta_{n}+\theta_{s}\right)\right]}{\left[\left(\theta_{n}+\theta_{s}\right)\left(k+T-\theta_{n}\right)\right]^{2}} \\
=\frac{2 \theta_{n}+\theta_{s}-k-T}{\left[\left(\theta_{n}+\theta_{s}\right)\left(k+T-\theta_{n}\right)\right]^{2}}>0 \Longleftrightarrow \theta_{n}>\frac{k+T-\theta_{s}}{2}
\end{gathered}
$$




$$
\begin{aligned}
\frac{\partial E\left(b_{n}\right)}{\partial \theta_{n}}= & \frac{\theta_{s}+T}{\left(k+T-\theta_{n}\right)^{2}} \underline{b} \ln \left(\frac{P}{\underline{b}}\right)+ \\
& \frac{\theta_{s}+T}{k+T-\theta_{n}} \frac{\partial \underline{b}}{\partial \theta_{n}} \ln \left(\frac{P}{\underline{b}}\right)+ \\
& \frac{\theta_{s}+T}{k+T-\theta_{n}} \underline{b} \frac{\underline{b}}{P} \frac{\partial \underline{b}}{\partial \theta_{n}}-\frac{\partial F_{n}(P)}{\partial \theta_{n}}>0
\end{aligned}
$$

Where all the elements are positive and $-\frac{\partial F_{n}(P)}{\partial \theta_{n}}>0$ when $\theta_{n}<\frac{k+T-\theta_{s}}{2}$.

$$
\begin{gathered}
\frac{\partial E\left(b_{s}\right)}{\partial \theta_{n}}=\frac{1}{\left(T+\theta_{s}\right)} \underline{b} \ln \left(\frac{P}{\underline{b}}\right)+ \\
\frac{1}{\left(T+\theta_{s}\right)} \frac{\partial \underline{b}}{\partial \theta_{n}} \ln \left(\frac{P}{\underline{b}}\right)+ \\
\frac{1}{\left(T+\theta_{s}\right)} \underline{b} \frac{\underline{b}}{P} \frac{\partial \underline{b}}{\partial \theta_{n}}>0 \\
\frac{\partial \bar{\pi}_{n}}{\partial \theta_{n}}=P>0 \\
\frac{\partial \bar{\pi}_{s}}{\partial \theta_{n}}=\frac{P}{k}\left(\theta_{s}+T\right)>0
\end{gathered}
$$

Area $B 1$

$$
\begin{aligned}
& \frac{\partial \underline{b}}{\partial \theta_{n}}=\frac{P}{k}>0 \\
& \frac{\partial F_{n}(P)}{\partial \theta_{n}}=0 \\
\frac{\partial E\left(b_{n}\right)}{\partial \theta_{n}}= & \frac{\theta_{s}+T}{\left(k+T-\theta_{n}\right)^{2}} \underline{b} \ln \left(\frac{P}{\underline{b}}\right)+ \\
& \frac{\theta_{s}+T}{k+T-\theta_{n}} \frac{\partial \underline{b}}{\partial \theta_{n}} \ln \left(\frac{P}{\underline{b}}\right)+ \\
& \frac{\theta_{s}+T}{k+T-\theta_{n}} \underline{b} \frac{\underline{b}}{P} \frac{\partial \underline{b}}{\partial \theta_{n}}>0 \\
\frac{\partial E\left(b_{s}\right)}{\partial \theta_{n}}= & \frac{k}{\left(k+T-\theta_{n}\right)^{2}} \underline{b} \ln \left(\frac{P}{\underline{b}}\right)+ \\
& \frac{k}{k+T-\theta_{n}} \frac{\partial \underline{b}}{\partial \theta_{n}} \ln \left(\frac{P}{\underline{b}}\right)+ \\
& \frac{k}{k+T-\theta_{n}} \underline{b} \frac{\underline{b}}{P} \frac{\partial \underline{b}}{\partial \theta_{n}}>0
\end{aligned}
$$




$$
\begin{gathered}
\frac{\partial \bar{\pi}_{n}}{\partial \theta_{n}}=P>0 \\
\frac{\partial \bar{\pi}_{s}}{\partial \theta_{n}}=\frac{P}{k}\left(\theta_{s}+T\right)>0
\end{gathered}
$$

Corollary 2. Area $A 1$.

$$
\begin{gathered}
\frac{\partial \underline{b}}{\partial \theta_{s}}=\frac{-P\left(\theta_{n}-T\right)}{\left(\theta_{n}+\theta_{s}\right)^{2}}<0 \\
\frac{\partial F_{n}(P)}{\partial \theta_{s}}=\frac{2\left(\theta_{s}+T\right)\left[\left(\theta_{n}+\theta_{s}\right)\left(k+T-\theta_{n}\right)\right]-\left(\theta_{s}+T\right)^{2}\left[k+T-\theta_{n}\right]}{\left[\left(\theta_{n}+\theta_{s}\right)\left(k+T-\theta_{n}\right)\right]^{2}} \\
=\frac{\frac{\left(\theta_{s}+T\right)\left(k+T-\theta_{n}\right)\left(2 \theta_{n}+\theta_{s}-T\right)}{\left[\left(\theta_{n}+\theta_{s}\right)\left(k+T-\theta_{n}\right)\right]^{2}}>0}{\frac{\partial E\left(b_{n}\right)}{\partial \theta_{s}}=\frac{1}{k+T-\theta_{n}} \underline{b} \ln \left(\frac{P}{\underline{b}}\right)+} \\
\frac{\theta_{s}+T}{k+T-\theta_{n}} \frac{\partial \underline{b}}{\partial \theta_{s}} \ln \left(\frac{P}{\underline{b}}\right) \\
\frac{\theta_{s}+T}{k+T-\theta_{n}} \underline{b} \frac{\underline{b}}{P} \frac{\partial \underline{b}}{\partial \theta_{s}}-\frac{\partial F_{n}(P)}{\partial \theta_{s}}<0
\end{gathered}
$$

Where, $\frac{\theta_{s}+T}{k+T-\theta_{n}} \frac{\partial \underline{b}}{\partial \theta_{s}} \ln \left(\frac{P}{\underline{b}}\right), \frac{\theta_{s}+T}{k+T-\theta_{n}} \underline{b} \frac{\underline{b}}{P} \frac{\partial \underline{b}}{\partial \theta_{s}}$ and $\frac{\partial F_{n}(P)}{\partial \theta_{s}}$ are negative and $\frac{1}{k+T-\theta_{n}} \underline{b} \ln \left(\frac{P}{\underline{b}}\right)$ is positive.

$$
\begin{gathered}
\frac{\partial E\left(b_{s}\right)}{\partial \theta_{s}}=\frac{T-\theta_{n}}{\left(T+\theta_{s}\right)^{2}} \underline{b} \ln \left(\frac{P}{\underline{b}}\right)+ \\
\frac{\theta_{s}+\theta_{n}}{T+\theta_{s}} \frac{\partial \underline{b}}{\partial \theta_{s}} \ln \left(\frac{P}{\underline{b}}\right) \\
\frac{\theta_{s}+\theta_{n}}{T+\theta_{s}} \underline{b} \frac{\underline{b}}{P} \frac{\partial \underline{b}}{\partial \theta_{s}}<0 \\
\frac{\partial \bar{\pi}_{n}}{\partial \theta_{s}}=0 \\
\frac{\partial \bar{\pi}_{s}}{\partial \theta_{s}=} \frac{-P\left(\theta_{n}-T\right)}{\left(\theta_{n}+\theta_{s}\right)^{2}}\left(\theta_{s}+T\right)+\frac{-P\left(\theta_{n}-T\right)}{\left(\theta_{n}+\theta_{s}\right)}>0
\end{gathered}
$$

Area $B 1$. 


$$
\begin{gathered}
\frac{\partial \underline{b}}{\partial \theta_{s}}=0 \\
\frac{\partial F_{n}(P)}{\partial \theta_{s}}=\frac{1}{k}>0 \\
\frac{\partial E\left(b_{n}\right)}{\partial \theta_{s}}=\frac{1}{k+T-\theta_{n}} \frac{P\left(\theta_{n}-T\right)}{k} \ln \left(\frac{P}{b}\right)-\frac{P}{k}>0 \Leftrightarrow \\
\frac{\left(\theta_{n}-T\right)}{k+T-\theta_{n}} \ln \left(\frac{P}{b}\right)>1 \\
\frac{\partial E\left(b_{s}\right)}{\partial \theta_{s}}=0 \\
\frac{\partial \bar{\pi}_{n}}{\partial \theta_{s}}=0 \\
\frac{\partial \bar{\pi}_{s}}{\partial \theta_{s}}=\underline{b}>0
\end{gathered}
$$

\section{Annex 2. The effect of transmission capacity constraints and trans-}

mission costs

\section{Proposition 2.}

When the auction is uniform. Using lemma three, the proof is straight forward.

When the demand is low (area A, figure 6).

The pure strategies equilibrium is defined by

$$
b_{s}=b_{n}=\frac{t \theta_{n}}{\theta_{s}+\theta_{n}}
$$

The equilibrium price is $\frac{t \theta_{n}}{\theta_{s}+\theta_{n}}$.

The equilibrium profit is:

$$
\pi_{n}=\left(\theta_{s}+\theta_{n}\right) \frac{t \theta_{n}}{\theta_{s}+\theta_{n}}-t \theta_{s}=t\left(\theta_{n}-\theta_{s}\right) ; \pi_{s}=\left(\theta_{s}+\theta_{n}\right) \frac{t \theta_{n}}{\theta_{s}+\theta_{n}}-t \theta_{n}=0
$$

The electricity flows from the low-demand market into the high-demand market. 
When the demand is intermediate (area A1, figure 6). There exist two possible types of equilibria. When the transmission cost is low, multiplicity of equilibria exist where the supplier located in the high-demand market satisfy the residual demand. When the transmission cost is high, the equilibrium is unique and the supplier located in the highdemand market satisfy the demand in both markets.

When the transmission cost is low, the pure strategies equilibrium is defined by

$$
b_{s}=b_{n}=\frac{t T}{\theta_{s}+T}
$$

The equilibrium price is $\frac{t T}{\theta_{s}+T}$

The equilibrium profit is:

$$
\pi_{n}=\left(\theta_{s}+\theta_{n}\right) \frac{t T}{\theta_{s}+T}-t \theta_{s}>0 ; \pi_{s}=\left(\theta_{s}+T\right) \frac{t T}{\theta_{s}+T}-t T=0
$$

The electricity flows from the high-demand market to the low-demand market.

When the transmission cost is high, multiplicity of pure strategies equilibria exist where the strategies are defined by

$$
b_{n}=P ; \quad b_{s} \in\left[0, \frac{P\left(\theta_{n}-T\right)+t \theta_{s}}{\theta_{s}+\theta_{n}}\right]
$$

The equilibrium price is $P$

The equilibrium profit is:

$$
\pi_{n}=P\left(\theta_{n}-T\right) ; \pi_{s}=P\left(\theta_{s}+T\right)-t T
$$

The electricity flows from the low-demand market to the high-demand market.

When the demand is intermediate (area B1a, figure 6) multiplicity of pure strategies equilibria exist.

The pure strategies equilibrium in the first type of equilibrium is defined by

$$
b_{n}=P ; \quad b_{s} \in\left[0, \frac{P\left(\theta_{n}-T\right)+t\left(k-\theta_{n}\right)}{k}\right]
$$

The equilibrium price is $P$

The equilibrium profit is:

$$
\pi_{n}=P\left(\theta_{n}-T\right) ; \pi_{s}=P\left(\theta_{s}+T\right)-t T
$$

The electricity flows from the low-demand market to the high-demand market.

The pure strategies equilibrium in the second type of equilibrium is defined by

$$
b_{n} \in\left[0, \frac{P\left(\theta_{s}+\theta_{n}-k\right)+t T}{\theta_{s}+T}\right] ; b_{s}=P
$$


The equilibrium price is $P$

The equilibrium profit is:

$$
\pi_{n}=P k-t\left(k-\theta_{n}\right) ; \pi_{s}=P\left(\theta_{s}+\theta_{n}-k\right)
$$

The electricity flows from the high-demand market to the low-demand market.

When the demand is intermediate (area B1b, figure 6) multiplicity of pure strategies equilibria exist.

The pure strategies equilibrium in the first type of equilibrium is defined by

$$
b_{n}=P ; \quad b_{s} \in\left[0, \frac{P\left(\theta_{n}-T\right)}{k}\right]
$$

The equilibrium price is $P$

The equilibrium profit is:

$$
\pi_{n}=P\left(\theta_{n}-T\right) ; \pi_{s}=P\left(\theta_{s}+T\right)-t T
$$

The electricity flows from the low-demand market to the high-demand market.

The pure strategies equilibrium in the second type of equilibrium is defined by

$$
b_{n} \in\left[0, \frac{P\left(\theta_{s}+\theta_{n}-k\right)+t T}{\theta_{s}+T}\right] ; b_{s}=P
$$

The equilibrium price is $P$

The equilibrium profit is:

$$
\pi_{n}=P k ; \pi_{s}=P\left(\theta_{s}+\theta_{n}-k\right)
$$

The electricity flows from the high-demand market to the low-demand market.

When the demand is intermediate (area B2a, figure 6) multiplicity of pure strategies equilibria exist.

The pure strategies equilibrium is defined by

$$
b_{i}=P ; \quad b_{j} \in\left[0, \frac{P\left(\theta_{j}+\theta_{i}-k\right)+t\left(k-\theta_{i}\right)}{k}\right]
$$

The equilibrium price is $P$

The equilibrium profit is:

$$
\pi_{i}=P\left(\theta_{j}+\theta_{i}-k\right) ; \pi_{j}=P k-t\left(k-\theta_{j}\right)
$$

When the demand is intermediate (area B2b, figure 6) multiplicity of pure strategies equilibria exist. 
The pure strategies equilibrium in the first type of equilibrium is defined by

$$
b_{i}=P ; \quad b_{j} \in\left[0, \frac{P\left(\theta_{j}+\theta_{i}-k\right)}{k}\right]
$$

The equilibrium price is $P$

The equilibrium profit is:

$$
\pi_{i}=P\left(\theta_{j}+\theta_{i}-k\right) ; \pi_{j}=P k-t\left(k-\theta_{j}\right)
$$

The pure strategies equilibrium in the second type of equilibrium is defined by

$$
b_{i} \in\left[0, \frac{P\left(\theta_{j}+\theta_{i}-k\right)+t\left(k-\theta_{j}\right)}{k}\right] ; b_{j}=P
$$

The equilibrium price is $P$

The equilibrium profit is:

$$
\pi_{i}=P k ; \pi_{j}=P\left(\theta_{j}+\theta_{i}-k\right)
$$

\section{When the auction is discriminatory.}

Proposition 2. Characterization of the equilibrium in the presence of transmission constraints and transmission costs.

For further reference:

$$
\begin{aligned}
H_{i}(\theta, P, T, t) & =\max \left\{0, \theta_{i}-T, \theta_{j}+\theta_{i}-k\right\} \\
H t_{i}(\theta, P, T, t) & =\max \left\{0, \theta_{j}-k\right\} \\
L_{i}(\theta, P, T, t) & =\min \left\{\theta_{i}+\theta_{j}, \theta_{i}+T, k\right\} \\
L t_{i}(\theta, P, T, t) & =\max \left\{0, \min \left\{\theta_{i}, T, k-\theta_{i}\right\}\right\}
\end{aligned}
$$

I proceed as in proposition one: first, I work out the general formulas of the lower bound of the support, the cumulative distribution function, the probability distribution function, the expected equilibrium price and the expected profit; second, I work out the particular formulas associated with each single area in figure 6 .

Lower Bound of the Support. The lower bound of the support is defined according to lemma four.

Cumulative Distribution Function.

In the first step, the payoff function for any firm is:

$$
\begin{aligned}
\pi_{i}(b)= & F_{j}(b)\left[b\left(H_{i}(\theta, P, T, t)\right)-t\left(H t_{i}(\theta, P, T, t)\right)\right]+ \\
& \left(1-F_{j}(b)\right)\left[b\left(L_{i}(\theta, P, T, t)\right)-t\left(L t_{i}(\theta, P, T, t)\right)\right]= \\
= & -F_{j}(b)\left[b\left(L_{i}(\theta, P, T, t)\right)-t\left(L t_{i}(\theta, P, T, t)\right)-b\left(H_{i}(\theta, P, T, t)\right)+t\left(H t_{i}(\theta, P, T, t)\right)\right] \\
& b\left(L_{i}(\theta, P, T, t)\right)-t\left(L t_{i}(\theta, P, T, t)\right)
\end{aligned}
$$


In the second step, $\pi_{i}(b)=\bar{\pi}_{i} \forall b \in S_{i}, i=n, s$, where $S_{i}$ is the support of the mixed strategy. Then,

$$
\begin{aligned}
= & -F_{j}(b)\left[b\left(L_{i}(\theta, P, T, t)\right)-t\left(L t_{i}(\theta, P, T, t)\right)-b\left(H_{i}(\theta, P, T, t)\right)+t\left(H t_{i}(\theta, P, T, t)\right)\right] \\
& b\left(L_{i}(\theta, P, T, t)\right)-t\left(L t_{i}(\theta, P, T, t)\right) \Rightarrow \\
F_{j}(b)= & \frac{b\left(L_{i}(\theta, P, T, t)\right)-t\left(L t_{i}(\theta, P, T, t)\right)-\bar{\pi}_{i}}{b\left[L_{i}(\theta, P, T, t)-H_{i}(\theta, P, T, t)\right]-t\left[L t_{i}(\theta, P, T, t)-H t_{i}(\theta, P, T, t)\right]}
\end{aligned}
$$

In the third step, at $\underline{b}, F_{i}(\underline{b})=0 \forall i=n, s$. Then,

$$
\bar{\pi}_{i}=b\left(L_{i}(\theta, P, T, t)\right)-t\left(L t_{i}(\theta, P, T, t)\right)
$$

Fourth step, plugging 10 into 9, I obtain the mixed strategies for both firms.

$$
\begin{aligned}
F_{j}(b)= & \frac{(b-\underline{b}) L_{i}(\theta, P, T, t)}{b\left[L_{i}(\theta, P, T, t)-H_{i}(\theta, P, T, t)\right]-t\left[L t_{i}(\theta, P, T, t)-H t_{i}(\theta, P, T, t)\right]}= \\
& \forall i=n, s
\end{aligned}
$$

Probability Distribution Function.

$$
\begin{aligned}
f_{j}(b)= & \frac{\partial F_{j}(b)}{\partial b} \\
= & \frac{L_{i}(\cdot)\left[\underline{b}\left[L_{i}(\theta, P, T, t)-H_{i}(\theta, P, T, t)\right]-t\left[L t_{i}(\theta, P, T, t)-H t_{i}(\theta, P, T, t)\right]\right]}{\left[b\left[L_{i}(\theta, P, T, t)-H_{i}(\theta, P, T, t)\right]-t\left[L t_{i}(\theta, P, T, t)-H t_{i}(\theta, P, T, t)\right]\right]^{2}} \\
& \forall i=n, s
\end{aligned}
$$

For further reference:

$$
\begin{aligned}
n(\cdot) & =L_{i}(\cdot)\left[\underline{b}\left[L_{i}(\theta, P, T, t)-H_{i}(\theta, P, T, t)\right]-t\left[L t_{i}(\theta, P, T, t)-H t_{i}(\theta, P, T, t)\right]\right] \\
d_{1}(\cdot) & =\left[L_{i}(\theta, P, T, t)-H_{i}(\theta, P, T, t)\right] \\
d_{2}(\cdot) & =\left[L t_{i}(\theta, P, T, t)-H t_{i}(\theta, P, T, t)\right]
\end{aligned}
$$

Expected Equilibrium Bid.

$$
\begin{aligned}
E_{j}(b) & =\int_{\underline{b}}^{P} b f_{j}(b) \partial b \\
& =\int_{\underline{b}}^{P} \frac{b(n(\cdot))}{\left[b\left(d_{1}(\cdot)\right)-t\left(d_{2}(\cdot)\right)\right]^{2}} \partial b+P\left(1-F_{j}(P)\right) \forall i=n, s
\end{aligned}
$$

I solve this equation by substitution of variables. In particular:

$$
\begin{aligned}
U & =\left[b\left(d_{1}(\cdot)\right)-t\left(d_{2}(\cdot)\right)\right] \Rightarrow b=\frac{U+t\left(d_{2}(\cdot)\right)}{d_{1}(\cdot)} \\
\frac{\partial U}{\partial b} & =d_{1} \Rightarrow \partial b=\frac{\partial U}{\partial d_{1}}
\end{aligned}
$$


Therefore:

$$
\begin{aligned}
E_{j}(b) & =\int_{\underline{b}}^{P} \frac{\left(\frac{U+t\left(d_{2}(\cdot)\right)}{d_{1}(\cdot)}\right) n(\cdot)}{U^{2}} \frac{\partial U}{d_{1}(\cdot)}+P\left(1-F_{j}(P)\right) \\
& =\frac{n(\cdot)}{d_{1}(\cdot)}\left[\int_{\underline{b}}^{P} \frac{U \partial U}{U^{2}}+\int_{\underline{b}}^{P} \frac{t\left(d_{2}(\cdot)\right) \partial U}{U^{2}}\right]+P\left(1-F_{j}(P)\right) \\
& =\frac{n(\cdot)}{d_{1}(\cdot)^{2}}\left[\ln (U)-\frac{t\left(d_{2}(\cdot)\right)}{U}\right]_{\underline{b}}^{P}+P\left(1-F_{j}(P)\right)
\end{aligned}
$$

Substituting again:

$$
\begin{aligned}
E_{j}(b)= & \frac{n(\cdot)}{d_{1}(\cdot)^{2}} \\
& {\left[\ln \left(\frac{P\left(d_{1}(\cdot)\right)-t\left(d_{2}(\cdot)\right)}{\underline{b}\left(d_{1}(\cdot)\right)-t\left(d_{2}(\cdot)\right)}\right)-\frac{t\left(d_{2}(\cdot)\right)}{P\left(d_{1}(\cdot)\right)-t\left(d_{2}(\cdot)\right)}+\frac{t\left(d_{2}(\cdot)\right)}{\underline{b}\left(d_{1}(\cdot)\right)-t\left(d_{2}(\cdot)\right)}\right] } \\
& +P\left(1-F_{j}(P)\right)
\end{aligned}
$$

In the rest of the proof, I will work out the lower bound of the support, the cumulative distribution function, the probability distribution function, the expected equilibrium price and the expected profit for the different possible realizations of demands $\left(\theta_{s}, \theta_{n}\right)$ (figure 6.

Area $A 1$.

First, the lower bound of the support is:

$$
\begin{aligned}
\underline{b}_{n} \theta_{n}+\underline{b}_{n} \theta_{s}-t \theta_{s}=P\left(\theta_{n}-T\right) \Rightarrow \underline{b}_{n} & =\frac{P\left(\theta_{n}-T\right)+t \theta_{s}}{\theta_{n}+\theta_{s}} \\
\underline{b}_{s} \theta_{s}+\underline{b}_{s} T-t T=0 \Rightarrow \underline{b}_{s} & =\frac{t T}{\theta_{s}+T}
\end{aligned}
$$

Second, I work out the cumulative distribution function.

$$
\begin{gathered}
F_{s}(b)= \begin{cases}0 & \text { if } b<\underline{b} \\
\frac{(b-\underline{b})\left(\theta_{n}+\theta_{s}\right)}{b\left[\left(\theta_{s}+\theta_{n}\right)-\left(\theta_{n}-T\right)\right]-t \min \left\{\theta_{s}, k-\theta_{n}\right\}} & \text { if } b \in(\underline{b}, P) \\
1 & \text { if } b=P\end{cases} \\
F_{n}(b)= \begin{cases}0 & \text { if } b<\underline{b} \\
\frac{(b-\underline{b})\left(\theta_{s}+T\right)}{b\left(\theta_{s}+T\right)-t T} & \text { if } b \in(\underline{b}, P) \\
1 & \text { if } b=P\end{cases}
\end{gathered}
$$

Moreover, 


$$
\begin{aligned}
\text { If } \underline{b}_{n} \geq \underline{b}_{s} \Rightarrow F_{s}(P) & =1 \\
F_{n}(P) & =\frac{\left(P\left(\theta_{s}+T\right)-t \theta_{s}\right)\left(\theta_{s}+T\right)}{\left(P\left(\theta_{s}+T\right)-t T\right)\left(\theta_{s}+\theta_{n}\right)} \\
\text { If } \underline{b}_{n}<\underline{b}_{s} \Rightarrow F_{s}(P) & =\frac{\left(P\left(\theta_{s}+T\right)-t T\right)\left(\theta_{s}+\theta_{n}\right)}{\left(P\left(\theta_{s}+T\right)-t \theta_{s}\right)\left(\theta_{s}+T\right)} \\
F_{n}(P) & =1
\end{aligned}
$$

Third, the probability distribution function is equal to:

$$
\begin{gathered}
f_{s}(b)=\frac{\partial F_{s}(b)}{\partial b}=\frac{\left(\theta_{n}+\theta_{s}\right)\left(\underline{b}\left(\theta_{s}+T\right)-t \theta_{s}\right)}{\left(b\left(\theta_{s}+T\right)-t \theta_{s}\right)^{2}} \\
f_{n}(b)=\frac{\partial F_{n}(b)}{\partial b}=\frac{\left(\theta_{s}+T\right)\left(\underline{b}\left(\theta_{s}+T\right)-t T\right)}{\left(b\left(\theta_{s}+T\right)-t T\right)^{2}}
\end{gathered}
$$

Fourth, the expected bid is determined by:

$$
\begin{aligned}
E_{s}(b)= & \int_{\underline{b}}^{P} b f_{s}\left(b_{s}\right) \partial b=\int_{\underline{b}}^{P} b \frac{\left(\theta_{n}+\theta_{s}\right)\left(\underline{b}\left(\theta_{s}+T\right)-t \theta_{s}\right)}{\left(b\left(\theta_{s}+T\right)-t \theta_{s}\right)^{2}}+\left(1-F_{s}(P)\right) P \\
= & \frac{\left(\theta_{n}+\theta_{s}\right)\left(\underline{b}\left(\theta_{s}+T\right)-t \theta_{s}\right)}{\left(\theta_{s}+T\right)^{2}} \\
& {\left[\ln \left(\frac{P\left(\theta_{s}+T\right)-t \theta_{s}}{\underline{b}\left(\theta_{s}+T\right)-t \theta_{s}}\right)-\frac{t \theta_{s}}{P\left(\theta_{s}+T\right)-t \theta_{s}}+\frac{t \theta_{s}}{\underline{b}\left(\theta_{s}+T\right)-t \theta_{s}}\right] } \\
& +\left(1-F_{s}(P)\right) P \\
E_{n}(b)= & \int_{\underline{b}}^{P} b f_{n}\left(b_{s}\right) \partial b=\int_{\underline{b}}^{P} b \frac{\left(\theta_{s}+T\right)\left(\underline{b}\left(\theta_{s}+T\right)-t T\right)}{\left(b\left(\theta_{s}+T\right)-t T\right)^{2}}+\left(1-F_{n}(P)\right) P \\
= & \frac{\left(\underline{b}\left(\theta_{s}+T\right)-t T\right)}{\left(\theta_{s}+T\right)} \\
& {\left[\ln \left(\frac{P\left(\theta_{s}+T\right)-t T}{\underline{b}\left(\theta_{s}+T\right)-t T}\right)-\frac{t T}{P\left(\theta_{s}+T\right)-t T}+\frac{t T}{\underline{b}\left(\theta_{s}+T\right)-t T}\right] } \\
& +\left(1-F_{n}(P)\right) P
\end{aligned}
$$

In equation 14, I have solved by substituting variables:

$$
\begin{aligned}
U & =b\left(\theta_{s}+T\right)-t \theta_{s} \Rightarrow b=\frac{U+t \theta_{s}}{\theta_{s}+T} \\
\frac{\partial U}{\partial b} & =\theta_{s}+T \Rightarrow \partial b=\frac{\partial U}{\theta_{s}+T} \\
\text { and } & \\
U & =b\left(\theta_{s}+T\right)-t T \Rightarrow b=\frac{U+t T}{\theta_{s}+T} \\
\frac{\partial U}{\partial b} & =\theta_{s}+T \Rightarrow \partial b=\frac{\partial U}{\theta_{s}+T}
\end{aligned}
$$


Fifth, the expected profit is defined by equation 10 and is equal to $\bar{\pi}_{n}=\underline{b}\left(\theta_{s}+\theta_{n}\right)-t \theta_{s}$ and $\bar{\pi}_{s}=\underline{b}\left(\theta_{s}+T\right)-t T$.

Area B1a.

First, the lower bound of the support is:

$$
\begin{aligned}
\underline{b}_{n} \theta_{n}+\underline{b}_{n}\left(k-\theta_{n}\right)-t\left(k-\theta_{n}\right)=P\left(\theta_{n}-T\right) \Rightarrow \underline{b}_{n} & =\frac{P\left(\theta_{n}-T\right)+t\left(k-\theta_{n}\right)}{k} \\
\underline{b}_{s} \theta_{s}+\underline{b}_{s} T-t T=P\left(\theta_{s}+\theta_{n}-k\right) \Rightarrow \underline{b}_{s} & =\frac{P\left(\theta_{s}+\theta_{n}-k\right)+t T}{\theta_{s}+T}
\end{aligned}
$$

Second, I work out the cumulative distribution function.

$$
\begin{gathered}
F_{s}(b)= \begin{cases}0 & \text { if } b<\underline{b} \\
\frac{(b-\underline{b}) k}{b\left(k+T-\theta_{n}\right)-t\left(k-\theta_{n}\right)} & \text { if } b \in(\underline{b}, P) \\
1 & \text { if } b=P\end{cases} \\
F_{n}(b)= \begin{cases}0 & \text { if } b<\underline{b} \\
\frac{(b-\underline{b})\left(\theta_{s}+T\right)}{b\left(k+T-\theta_{n}\right)-t T} & \text { if } b \in(\underline{b}, P) \\
1 & \text { if } b=P\end{cases}
\end{gathered}
$$

Moreover,

$$
\begin{aligned}
\text { If } \underline{b}_{n} \geq \underline{b}_{s} \Rightarrow F_{s}(P) & =1 \\
F_{n}(P) & =\frac{\left(P\left(k+T-\theta_{n}\right)-t\left(k-\theta_{n}\right)\right)\left(\theta_{s}+T\right)}{\left(P\left(k+T-\theta_{n}\right)-t T\right) k} \\
\text { If } \underline{b}_{n}<\underline{b}_{s} \Rightarrow F_{s}(P) & =\frac{\left(P\left(k+T-\theta_{n}\right)-t T\right) k}{\left(P\left(k+T-\theta_{n}\right)-t\left(k-\theta_{n}\right)\right)\left(\theta_{s}+T\right)} \\
F_{n}(P) & =1
\end{aligned}
$$

Third, the probability distribution function is equal to:

$$
\begin{array}{r}
f_{s}(b)=\frac{\partial F_{s}(b)}{\partial b}=\frac{k\left(\underline{b}\left(k+T-\theta_{n}\right)-t\left(k-\theta_{n}\right)\right)}{\left(b\left(k+T-\theta_{n}\right)-t\left(k-\theta_{n}\right)\right)^{2}} \\
f_{n}(b)=\frac{\partial F_{n}(b)}{\partial b}=\frac{\left(\theta_{s}+T\right)\left(\underline{b}\left(\theta_{s}+T\right)-t T\right)}{\left(b\left(\theta_{s}+T\right)-t T\right)^{2}}
\end{array}
$$

Fourth, the expected bid is determined by: 


$$
\begin{aligned}
E_{s}(b)= & \int_{\underline{b}}^{P} b f_{s}\left(b_{s}\right) \partial b=\int_{\underline{b}}^{P} b \frac{k\left(\underline{b}\left(k+T-\theta_{n}\right)-t\left(k-\theta_{n}\right)\right)}{\left(b\left(k+T-\theta_{n}\right)-t\left(k-\theta_{n}\right)\right)^{2}}+\left(1-F_{s}(P)\right) P \\
= & \frac{k\left(\underline{b}\left(k+T-\theta_{n}\right)-t\left(k-\theta_{n}\right)\right)}{\left(k+T-\theta_{n}\right)^{2}} \\
& {\left[\ln \left(\frac{P\left(k+T-\theta_{n}\right)-t\left(k-\theta_{n}\right)}{\underline{b}\left(k+T-\theta_{n}\right)-t\left(k-\theta_{n}\right)}\right)\right] } \\
& {\left[-\frac{t\left(k-\theta_{n}\right)}{P\left(k+T-\theta_{n}\right)-t\left(k-\theta_{n}\right)}+\frac{t\left(k-\theta_{n}\right)}{\underline{b}\left(k+T-\theta_{n}\right)-t\left(k-\theta_{n}\right)}\right] } \\
& +\left(1-F_{s}(P)\right) P \\
E_{n}(b)= & \int_{\underline{b}}^{P} b f_{n}\left(b_{s}\right) \partial b=\int_{\underline{b}}^{P} b \frac{\left(\theta_{s}+T\right)\left(\underline{b}\left(k+T-\theta_{n}\right)-t T\right)}{\left(b\left(k+T-\theta_{n}\right)-t T\right)^{2}}+\left(1-F_{n}(P)\right) P \\
= & \frac{\left(\theta_{s}+T\right)\left(\underline{b}\left(k+T-\theta_{n}\right)-t T\right)}{\left(k+T-\theta_{n}\right)^{2}} \\
& {\left[\ln \left(\frac{P\left(k+T-\theta_{n}\right)-t T}{\underline{b}\left(k+T-\theta_{n}\right)-t T}\right)-\frac{t T}{P\left(k+T-\theta_{n}\right)-t T}+\frac{t}{b\left(k+T-\theta_{n}\right)-t T}\right] } \\
& +\left(1-F_{n}(P)\right) P
\end{aligned}
$$

In equations 15, I have solved by substituting variables:

$$
\begin{aligned}
U & =b\left(k+T-\theta_{n}\right)-t\left(k-\theta_{n}\right) \Rightarrow b=\frac{U+t\left(k-\theta_{n}\right)}{k+T-\theta_{n}} \\
\frac{\partial U}{\partial b} & =k+T-\theta_{n} \Rightarrow \partial b=\frac{\partial U}{k+T-\theta_{n}} \\
\text { and } & \\
U & =b\left(k+T-\theta_{n}\right)-t T \Rightarrow b=\frac{U+t T}{k+T-\theta_{n}} \\
\frac{\partial U}{\partial b} & =k+T-\theta_{n} \Rightarrow \partial b=\frac{\partial U}{k+T-\theta_{n}}
\end{aligned}
$$

Fifth, the expected profit is defined by equation 10 and is equal to $\bar{\pi}_{n}=\underline{b} k-t\left(k-\theta_{n}\right)$ and $\bar{\pi}_{s}=\underline{b}\left(\theta_{s}+T\right)-t T$.

Area B1b.

First, the lower bound of the support is:

$$
\begin{aligned}
\underline{b}_{n} k=P\left(\theta_{n}-T\right) & \underline{b}_{n}=\frac{P\left(\theta_{n}-T\right)}{k} \\
\underline{b}_{s} \theta_{s}+\underline{b}_{s} T-t T=P\left(\theta_{s}+\theta_{n}-k\right)-t\left(\theta_{n}-k\right) \underline{b}_{s} & =\frac{P\left(\theta_{s}+\theta_{n}-k\right)+t\left(k+T-\theta_{n}\right)}{\theta_{s}+T}
\end{aligned}
$$

Second, I work out the cumulative distribution function. 


$$
\begin{array}{r}
F_{s}(b)= \begin{cases}0 & \text { if } b<\underline{b} \\
\frac{(b-\underline{b}) k}{b\left(k+T-\theta_{n}\right)} & \text { if } b \in(\underline{b}, P) \\
1 & \text { if } b=P\end{cases} \\
F_{n}(b)= \begin{cases}0 & \text { if } b<\underline{b} \\
\frac{(b-\underline{b})\left(\theta_{s}+T\right)}{b\left(k+T-\theta_{n}\right)-t\left(T+k-\theta_{n}\right)} & \text { if } b \in(\underline{b}, P) \\
1 & \text { if } b=P\end{cases}
\end{array}
$$

Moreover,

$$
\begin{aligned}
\text { If } \underline{b}_{n} \geq \underline{b}_{s} \Rightarrow F_{s}(P) & =1 \\
F_{n}(P) & =\frac{P\left(k+T-\theta_{n}\right)\left(\theta_{s}+T\right)}{(P-t)\left(k+T-\theta_{n}\right) k} \\
\text { If } \underline{b}_{n}<\underline{b}_{s} \Rightarrow F_{s}(P) & =\frac{(P-t)\left(k+T-\theta_{n}\right) k}{P\left(k+T-\theta_{n}\right)\left(\theta_{s}+T\right)} \\
F_{n}(P) & =1
\end{aligned}
$$

Third, the probability distribution function is equal to:

$$
\begin{array}{r}
f_{s}(b)=\frac{\partial F_{s}(b)}{\partial b}=\frac{\underline{b k}}{b^{2}\left(k+T-\theta_{n}\right)} \\
f_{n}(b)=\frac{\partial F_{n}(b)}{\partial b}=\frac{(\underline{b}-t)\left(\theta_{s}+T\right)}{(b-t)^{2}\left(k+T-\theta_{n}\right)}
\end{array}
$$

Fourth, the expected bid is determined by:

$$
\begin{aligned}
E_{s}(b) & =\int_{\underline{b}}^{P} b f_{s}\left(b_{s}\right) \partial b=\int_{\underline{b}}^{P} b \frac{\underline{b} k}{b^{2}\left(k+T-\theta_{n}\right)}+\left(1-F_{s}(P)\right) P \\
& =\frac{\underline{b} k}{\left(k+T-\theta_{n}\right)}\left[\ln \left(\frac{P}{\underline{b}}\right)\right]+\left(1-F_{s}(P)\right) P \\
E_{n}(b) & =\int_{\underline{b}}^{P} b f_{n}\left(b_{s}\right) \partial b=\int_{\underline{b}}^{P} b \frac{(\underline{b}-t)\left(\theta_{s}+T\right)}{(b-t)^{2}\left(k+T-\theta_{n}\right)}+\left(1-F_{n}(P)\right) P \\
& =\frac{(\underline{b}-t)\left(\theta_{s}+T\right)}{\left(k+T-\theta_{n}\right)}\left[\ln \left(\frac{P-t}{\underline{b}-t}\right)-\frac{t}{P-t}+\frac{t}{\underline{b}-t}\right]+\left(1-F_{n}(P)\right) P
\end{aligned}
$$

In equations 16, I have solved by substituting variables:

$$
\begin{aligned}
U & =b-t \Rightarrow b=U+t \\
\frac{\partial U}{\partial b} & =1 \Rightarrow \partial b=\partial U
\end{aligned}
$$


Fifth, the expected profit is defined by equation 10 and is equal to $\bar{\pi}_{n}=\underline{b} k$ and $\bar{\pi}_{s}=\underline{b}\left(\theta_{s}+T\right)-t T$.

Area B2a.

First, the lower bound of the support is:

$$
\begin{aligned}
\underline{b}_{n} \theta_{n}+\underline{b}_{n}\left(k-\theta_{n}\right)-t\left(k-\theta_{n}\right) & =P\left(\theta_{s}+\theta_{n}-k\right) \Rightarrow \underline{b}_{n}=\frac{P\left(\theta_{s}+\theta_{n}-k\right)+t\left(k-\theta_{n}\right)}{k} \\
\underline{b}_{s} \theta_{s}+\underline{b}_{s}\left(k-\theta_{s}\right)-t\left(k-\theta_{s}\right) & =P\left(\theta_{s}+\theta_{n}-k\right) \Rightarrow \underline{b}_{s}=\frac{P\left(\theta_{s}+\theta_{n}-k\right)+t\left(k-\theta_{s}\right)}{k}
\end{aligned}
$$

Second, I work out the cumulative distribution function.

$$
\begin{aligned}
& F_{s}(b)= \begin{cases}0 & \text { if } b<\underline{b} \\
\frac{(b-\underline{b}) k}{b\left(2 k-\theta_{n}-\theta_{s}\right)-t\left(k-\theta_{n}\right)} & \text { if } b \in(\underline{b}, P) \\
1 & \text { if } b=P\end{cases} \\
& F_{n}(b)= \begin{cases}0 & \text { if } b<\underline{b} \\
\frac{(b-\underline{b}) k}{b\left(2 k-\theta_{n}-\theta_{s}\right)-t\left(k-\theta_{s}\right)} & \text { if } b \in(\underline{b}, P) \\
1 & \text { if } b=P\end{cases}
\end{aligned}
$$

Moreover,

$$
\begin{aligned}
& F_{s}(P)=\frac{P\left(2 k-\theta_{n}-\theta_{s}\right)-t\left(k-\theta_{s}\right)}{P\left(2 k-\theta_{n}-\theta_{s}\right)-t\left(k-\theta_{n}\right)} \\
& F_{n}(P)=1
\end{aligned}
$$

Third, the probability distribution is equal to:

$$
\begin{aligned}
& f_{s}(b)=\frac{\partial F_{s}(b)}{\partial b}=\frac{k\left(\underline{b}\left(2 k-\theta_{n}-\theta_{s}\right)-t\left(k-\theta_{n}\right)\right)}{\left(b\left(2 k-\theta_{n}-\theta_{s}\right)-t\left(k-\theta_{n}\right)\right)^{2}} \\
& f_{n}(b)=\frac{\partial F_{n}(b)}{\partial b}=\frac{k\left(\underline{b}\left(2 k-\theta_{n}-\theta_{s}\right)-t\left(k-\theta_{s}\right)\right)}{\left(b\left(2 k-\theta_{n}-\theta_{s}\right)-t\left(k-\theta_{s}\right)\right)^{2}}
\end{aligned}
$$

Fourth, the expected bid is determined by: 


$$
\begin{aligned}
E_{s}(b)= & \int_{\underline{b}}^{P} b f_{s}\left(b_{s}\right) \partial b=\int_{\underline{b}}^{P} b \frac{k\left(\underline{b}\left(2 k-\theta_{n}-\theta_{s}\right)-t\left(k-\theta_{n}\right)\right)}{\left(b\left(2 k-\theta_{n}-\theta_{s}\right)-t\left(k-\theta_{n}\right)\right)^{2}}+\left(1-F_{s}(P)\right) P \\
= & \frac{k\left(\underline{b}\left(2 k-\theta_{n}-\theta_{s}\right)-t\left(k-\theta_{n}\right)\right)}{\left(b\left(2 k-\theta_{n}-\theta_{s}\right)-t\left(k-\theta_{n}\right)\right)^{2}} \\
& {\left[\ln \left(\frac{P\left(2 k-\theta_{n}-\theta_{s}\right)-t\left(k-\theta_{n}\right)}{\underline{b}\left(2 k-\theta_{n}-\theta_{s}\right)-t\left(k-\theta_{n}\right)}\right)\right] } \\
& {\left[-\frac{t\left(k-\theta_{n}\right)}{P\left(k+T-\theta_{n}\right)-t\left(k-\theta_{n}\right)}+\frac{t\left(k-\theta_{n}\right)}{\underline{b}\left(2 k-\theta_{n}-\theta_{s}\right)-t\left(k-\theta_{n}\right)}\right] } \\
& +\left(1-F_{s}(P)\right) P \\
E_{n}(b)= & \int_{\underline{b}}^{P} b f_{n}\left(b_{s}\right) \partial b=\int_{\underline{b}}^{P} b \frac{k\left(\underline{b}\left(2 k-\theta_{n}-\theta_{s}\right)-t\left(k-\theta_{s}\right)\right)}{\left(b\left(2 k-\theta_{n}-\theta_{s}\right)-t\left(k-\theta_{s}\right)\right)^{2}}+\left(1-F_{n}(P)\right) P \\
= & \frac{k\left(\underline{b}\left(2 k-\theta_{n}-\theta_{s}\right)-t\left(k-\theta_{s}\right)\right)}{\left(b\left(2 k-\theta_{n}-\theta_{s}\right)-t\left(k-\theta_{s}\right)\right)^{2}} \\
& {\left[\ln \left(\frac{P\left(2 k-\theta_{n}-\theta_{s}\right)-t\left(k-\theta_{s}\right)}{\underline{b}\left(2 k-\theta_{n}-\theta_{s}\right)-t\left(k-\theta_{s}\right)}\right)\right] } \\
& {\left[-\frac{t\left(k-\theta_{s}\right)}{P\left(k+T-\theta_{n}\right)-t\left(k-\theta_{s}\right)}+\frac{t\left(k-\theta_{s}\right)}{\underline{b}\left(2 k-\theta_{n}-\theta_{s}\right)-t\left(k-\theta_{s}\right)}\right] } \\
& +\left(1-F_{n}(P)\right) P
\end{aligned}
$$

where in equation 17, I have solved by substituting variables:

$$
\begin{aligned}
U & =b\left(2 k-\theta_{n}-\theta_{s}\right)-t\left(k-\theta_{n}\right) \Rightarrow b=\frac{U+t\left(k-\theta_{n}\right)}{2 k-\theta_{n}-\theta_{s}} \\
\frac{\partial U}{\partial b} & =2 k-\theta_{n}-\theta_{s} \Rightarrow \partial b=\frac{\partial U}{2 k-\theta_{n}-\theta_{s}} \\
\text { and } & \\
U & =b\left(2 k-\theta_{n}-\theta_{s}\right)-t\left(k-\theta_{s}\right) \Rightarrow b=\frac{U+t\left(k-\theta_{s}\right)}{2 k-\theta_{n}-\theta_{s}} \\
\frac{\partial U}{\partial b} & =2 k-\theta_{n}-\theta_{s} \Rightarrow \partial b=\frac{\partial U}{2 k-\theta_{n}-\theta_{s}}
\end{aligned}
$$

Fifth, the expected profit is defined by equation 10 and is equal to $\bar{\pi}_{n}=\underline{b} k-t\left(k-\theta_{n}\right)$ and $\bar{\pi}_{s}=\underline{b} k-t\left(k-\theta_{s}\right)$.

Area $B 2 b$.

First, the lower bound of the support is:

$$
\begin{aligned}
\underline{b}_{n} k=P\left(\theta_{s}+\theta_{n}-k\right) \underline{b}_{n} & =\frac{P\left(\theta_{s}+\theta_{n}-k\right)}{k} \\
\underline{b}_{s} \theta_{s}+\underline{b}_{s}\left(k-\theta_{s}\right)-t\left(k-\theta_{s}\right)= & \\
P\left(\theta_{s}+\theta_{n}-k\right)-t\left(\theta_{n}-k\right) \Rightarrow \underline{b}_{s} & =\frac{P\left(\theta_{s}+\theta_{n}-k\right)+t\left(2 k-\theta_{n}-\theta_{s}\right)}{k}
\end{aligned}
$$

Second, I work out the cumulative distribution function. 


$$
\begin{gathered}
F_{s}(b)= \begin{cases}0 & \text { if } b<\underline{b} \\
\frac{(b-\underline{b}) k}{b\left(2 k-\theta_{n}-\theta_{s}\right)} & \text { if } b \in(\underline{b}, P) \\
1 & \text { if } b=P\end{cases} \\
F_{n}(b)= \begin{cases}0 & \text { if } b<\underline{b} \\
\frac{(b-\underline{b}) k}{(b-t)\left(2 k-\theta_{n}-\theta_{s}\right)} & \text { if } b \in(\underline{b}, P) \\
1 & \text { if } b=P\end{cases}
\end{gathered}
$$

Moreover,

$$
\begin{aligned}
& F_{s}(P)=\frac{P\left(2 k-\theta_{n}-\theta_{s}\right)-t\left(2 k-\theta_{n}-\theta_{s}\right)}{P\left(2 k-\theta_{n}-\theta_{s}\right)} \\
& F_{n}(P)=1
\end{aligned}
$$

Third, the probability distribution function is equal to:

$$
\begin{array}{r}
f_{s}(b)=\frac{\partial F_{s}(b)}{\partial b}=\frac{\underline{b} k}{b^{2}\left(2 k-\theta_{n}-\theta_{s}\right)} \\
f_{n}(b)=\frac{\partial F_{n}(b)}{\partial b}=\frac{(\underline{b}-t) k}{(b-t)^{2}\left(2 k-\theta_{n}-\theta_{s}\right)}
\end{array}
$$

Fourth, the expected bid is determined by:

$$
\begin{aligned}
E_{s}(b) & =\int_{\underline{b}}^{P} b f_{s}\left(b_{s}\right) \partial b=\int_{\underline{b}}^{P} b \frac{\underline{b} k}{b^{2}\left(2 k-\theta_{n}-\theta_{s}\right)}+\left(1-F_{s}(P)\right) P \\
& =\frac{\underline{b} k}{\left(2 k-\theta_{n}-\theta_{s}\right)}\left[\ln \left(\frac{P}{\underline{b}}\right)\right]+\left(1-F_{s}(P)\right) P \\
E_{n}(b) & =\int_{\underline{b}}^{P} b f_{n}\left(b_{s}\right) \partial b=\int_{\underline{b}}^{P} b \frac{(\underline{b}-t) k}{(b-t)^{2}\left(2 k-\theta_{n}-\theta_{s}\right)}+\left(1-F_{n}(P)\right) P \\
& =\frac{(\underline{b}-t) k}{\left(2 k-\theta_{n}-\theta_{s}\right)}\left[\ln \left(\frac{P-t}{\underline{b}-t}\right)-\frac{t}{P-t}+\frac{t}{\underline{b}-t}\right]+\left(1-F_{n}(P)\right) P
\end{aligned}
$$

where in equations 18 , I have solved by substituting variables:

$$
\begin{aligned}
U & =b-t \Rightarrow b=U+t \\
\frac{\partial U}{\partial b} & =1 \Rightarrow \partial b=\partial U
\end{aligned}
$$

Fifth, the expected profit is defined by equation 10 and is equal to $\bar{\pi}_{n}=\underline{b} k$ and $\bar{\pi}_{s}=\underline{b} k-t\left(k-\theta_{s}\right)$.

\section{Proposition 3.}


Table 1: Increase in transmission costs $\triangle t$. Main variables. $\left(\theta_{s}=5, \theta_{n}=55, k=60\right.$, $T=40, c=0, P=7)$

\begin{tabular}{cccccccc}
\hline$t$ & $\underline{b}$ & $\bar{\pi}_{n}$ & $\bar{\pi}_{s}$ & $E_{n}(b)$ Ana. & $E_{n}(b) \operatorname{Sim}$. & $E_{s}(b)$ Ana. & $E_{s}(b) \operatorname{Sim}$. \\
\hline 0 & 1.751 & 105.06 & 78.79 & 4.1768 & 4.1769 & 3.2359 & 3.2362 \\
0.5 & 1.793 & 105.08 & 60.68 & 3.9247 & 3.9249 & 3.2660 & 3.2668 \\
1 & 1.834 & 105.05 & 42.53 & 3.5971 & 3.5974 & 3.2955 & 3.2955 \\
1.5 & 1.876 & 105.07 & 24.42 & 3.1477 & 3.1481 & 3.3255 & 3.3261 \\
2 & 1.918 & 105.1 & 6.31 & 2.4232 & 2.4236 & 3.3555 & 3.3567 \\
2.5 & 2.224 & 120.96 & 0 & 2.2332 & 2.2341 & 3.8482 & 3.8486 \\
\hline
\end{tabular}

Here $E_{n}(b)$ Ana. and $E_{s}(b)$ Ana. are the expected values obtained using the analytical expressions presented in Proposition two and $E_{n}(b)$ Sim. and $E_{s}(b)$ Sim. are the expected values obtained using the simulation explained in detail in Annex 3.

In the presence of transmission constraints and transmission costs, the size and the cost effects works in the opposite direction and as I have explained in the paper, this has important implications determining equilibrium market allocations. Due to the size and the cost effects, an increase in transmission costs induces non-monotonic changes in the main variables of the model and none clear conclusions can be obtained with a direct comparative static approach; i.e., using partial derivatives of the main variables of the model.

A direct approach to work out relevant changes on the main variables of the model is not afforded. However, proposition two provides a close form solution of the main variables of the model. Therefore, those formulas can be used to analyze the effect that a change in transmission costs have on the main variables of the model. Moreover, in Annex 3, I have developed a numerical method to work out the main variables of the model using the primitive cumulative distribution function. It can be checked in table 1 that both approaches generate the same results. Hence, an accurate numerical approach can be used to do the comparative static analysis.

Corollaries 3 and 4 . The same problem that the one presented in proposition three appears and I have done the comparative static using the close form solutions presented in proposition two and the numerical method explained in annex three.

\section{Annex 3. Expected equilibrium price: Simulation}

Propositions one and two fully characterize the equilibrium. However, due to the complexity of calculations and to ensure that I did not make any algebra mistake, I work out the expected bid for both firms using the algorithm presented in this annex. The algorithm is based on the cumulative distribution function that is the mixed strategies equilibrium from which the rest of the variables of the model are derived.

As can be observed in table 1, the differences between the expected bid using the analytical formulas from propositions one and two and using the algorithm proposed here 
are almost null.15

Figure 11: Expected bid. Simulation.

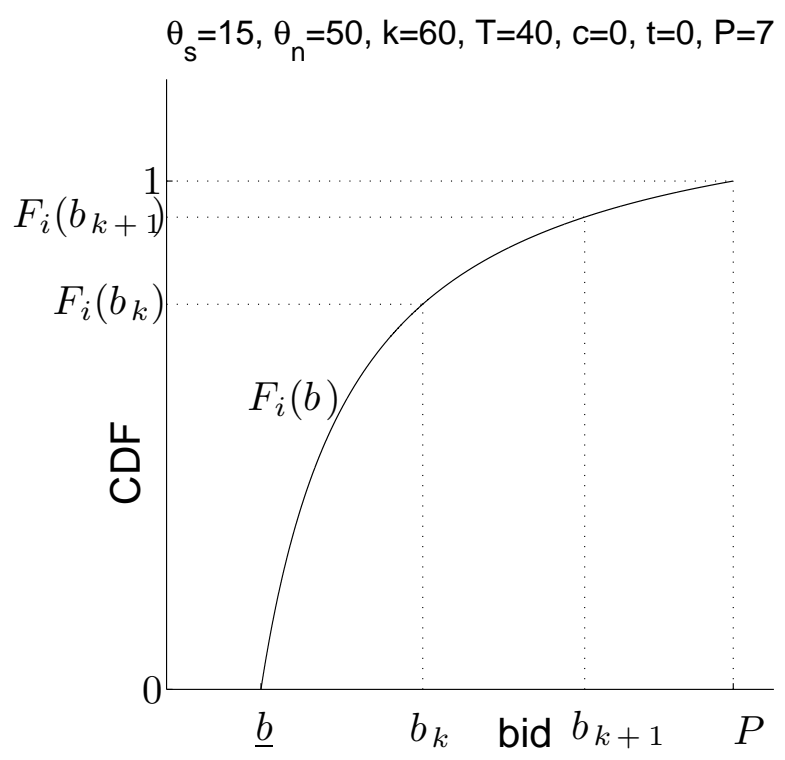

Algorithm: (figure 11)

1. I split the support of the mixed strategies equilibrium into $K$ grid values (where $K$ is a large number e.g., 5000 or 10000). I call each of these values $b_{i}(k) \forall i=s, n$.

2. For each $b_{i}(k)$, I work out $F_{i}\left(b_{i}(k)\right)$ using the formulas obtained in propositions one and two.

3. The probability assigned to $p_{i}\left(b_{i}(k)\right)$ equals the difference in the cumulative distribution function between two consecutive values $F_{i}\left(b_{i}(k+1)\right)-F_{i}\left(b_{i}(k)\right)$. Therefore, $p\left(b_{i}(k)\right)=F_{i}\left(b_{i}(k+1)\right)-F_{i}\left(b_{i}(k)\right)$. It is important to remark that one observation is lost during the process to work out the probabilities.

4. The expected value is the sum of each single bid multiplied by its probability: $E_{i}(b)=\sum_{k=0}^{K-1} b_{i}(k) p_{i}\left(b_{i}(k)\right) \forall i=s, n$

\section{Annex 4. Equilibrium in the presence of asymmetries in generation capacity and generation costs}

In the paper, I have shown that in the presence of transmission constraints and transmission costs, the discriminatory price auction performs better than the uniform price auction even when the suppliers are symmetric in generation capacity and generation costs. In this annex, I extend the results presented in Fabra et al. (2006) to analyze the effect that different types of asymmetries in generation capacity and generation costs have on equilibrium outcome allocations. I show that the performance of both type of auctions depends crucially on these parameters assumptions.

\footnotetext{
${ }^{15}$ I have applied this algorithm to work out the expected value for any realization of demand (all areas) and I have compared this with the analytical values and the results are almost identical.
} 
Figure 12: Output function for supplier $n .\left(k_{n}=k_{s}=60, T=60\right)$
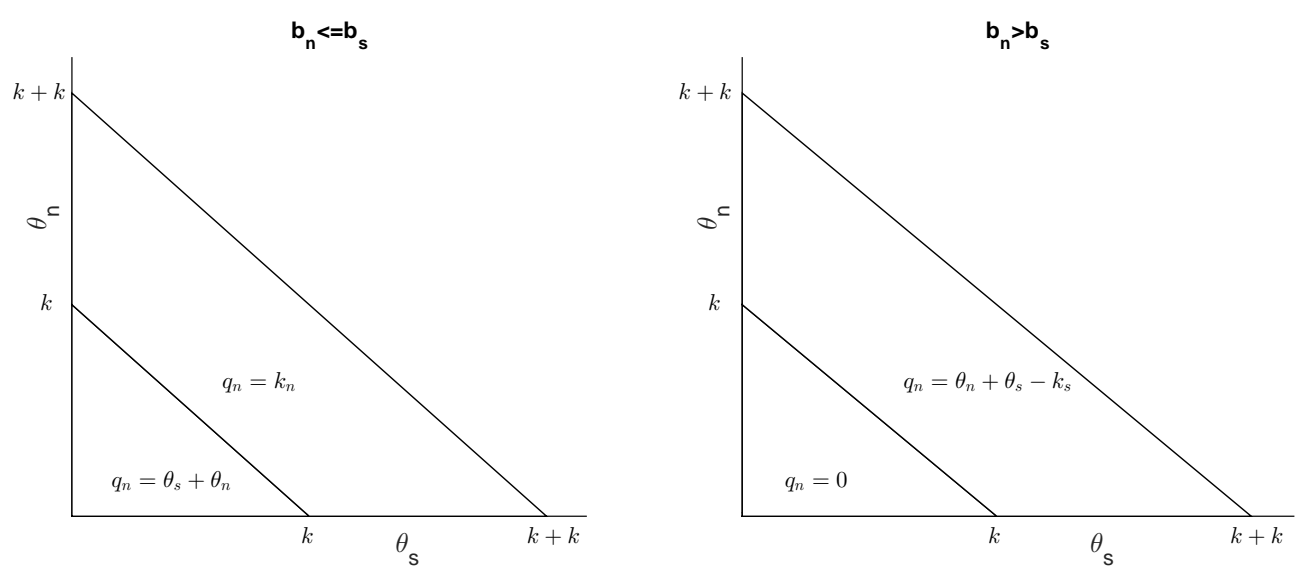

\section{The model}

Set up of the model. There exist two electricity markets, market North and market South, that are connected by a transmission line with capacity $T$.

There exist two duopolists with capacities $k_{n}$ and $k_{s}$, where subscript $n$ means that the supplier is located in market North and subscript $s$ means that the supplier is located in market South. The suppliers' marginal costs of production are $c_{n}$ and $c_{s}$. The level of demand in any period, $\theta_{n}$ in market North and $\theta_{s}$ in market South, is a random variable uniformly distributed that is independent across markets and independent of market price, i.e., perfectly inelastic. In particular, $\theta_{i} \in\left[\underline{\theta}_{i}, \bar{\theta}_{i}\right] \subseteq\left[0, k_{i}+k_{j}\right] \forall i=n, s$ is distributed according to some known distribution function $G\left(\theta_{i}\right), i=n, s, i \neq j$.

The capacity of the transmission line is larger than the installed capacity in each market $T \geq \max \left\{k_{s}, k_{n}\right\}$; i.e. the transmission line is never congested.

Timing of the game. Having observed the realization of demands $\theta \equiv\left(\theta_{s}, \theta_{n}\right)$, each supplier simultaneously and independently submits a bid specifying the minimum price at which it is willing to supply up to its capacity, $b_{i} \leq P, i=n, s$, where $P$ denotes the "market reserve price", possibly determined by regulation. Let $b \equiv\left(b_{s}, b_{n}\right)$ denote a bid profile. On basis of this profile, the auctioneer calls suppliers into operation. If suppliers submit different bids, the capacity of the lower-bidding supplier is dispatched first. If the two suppliers submit equal bids, then most efficient supplier (supplier $i$ ) is ranked first with probability $\rho_{i}=1$ if both suppliers are equally efficient $\rho_{i}=\frac{1}{2}$. The tie breaking rule implemented minimize production costs.

The output allocated to supplier $i, i=n, s$, denoted by $q_{i}(\theta, b)$, is given by (figure 13 summarizes supplier's $n$ output function)

$$
q_{i}(b ; \theta, T)= \begin{cases}\min \left\{\theta_{i}+\theta_{j}, k_{i}\right\} & \text { if } b_{i}<b_{j} \\ \rho_{i} \min \left\{\theta_{i}+\theta_{j}, k_{i}\right\}+\left[1-\rho_{i}\right] \max \left\{0, \theta_{i}+\theta_{j}-k_{j}\right\} & \text { if } b_{i}=b_{j} \\ \max \left\{0, \theta_{i}+\theta_{j}-k_{j}\right\} & \text { if } b_{i}>b_{j}\end{cases}
$$

Finally, the payments are worked out by the auctioneer. When the auctioneer runs 
Figure 13: Profit function for supplier $n .\left(k_{n}=k_{s}=60, T=60\right)$
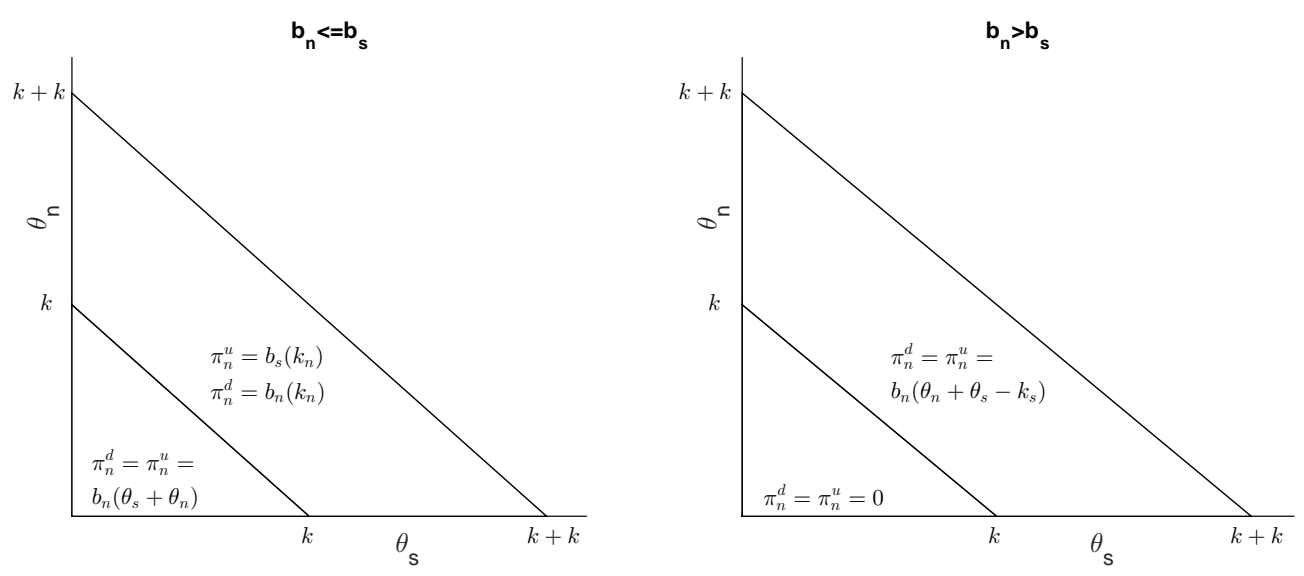

a discriminatory price auction, the price received by a supplier for any positive quantity dispatched by the auctioneer is equal to its own bid. Hence, for a given realization of $\theta \equiv\left(\theta_{j}, \theta_{i}\right)$ and a bid profile $b \equiv\left(b_{j}, b_{i}\right)$, supplier $i$ 's profits can be expressed as

$$
\pi_{i}^{d}(b ; \theta, T)=\left\{\left(b_{i}-c_{i}\right) q_{i}(b ; \theta, T)\right.
$$

In the case that the auctioneer runs an uniform price auction, the price received by a supplier for any positive quantity dispatched by the auctioneer is equal to the higher bid accepted in the auction. Hence, for a given realization of $\theta \equiv\left(\theta_{j}, \theta_{i}\right)$ and a bid profile $b \equiv\left(b_{j}, b_{i}\right)$, supplier $i$ 's profits can be expressed as (figure 12 summarizes supplier's $n$ profits for both types of auctions)

$$
\pi_{i}^{u}(b ; \theta, T)= \begin{cases}\left(b_{j}-c_{i}\right) \min \left\{\theta_{i}+\theta_{j}, k_{i}\right\} & \text { if } b_{i} \leq b_{j} \text { and } \theta_{i}+\theta_{j}>k_{i} \\ \left(b_{i}-c_{i}\right) q_{i}(b ; \theta, T) & \text { otherwise }\end{cases}
$$

\section{Equilibrium analysis}

In this section I characterize the equilibrium in the presence of asymmetries in generation capacity and production costs.

Lemma 5. When the realization of demands $\left(\theta_{j}, \theta_{i}\right)$ is low (area $A$ ), the equilibrium is in pure strategies for both types of auctions. When the realization of demands $\left(\theta_{j}, \theta_{i}\right)$ and the production costs are high a pure strategies equilibrium exists for both type of auctions. In the rest of the cases, multiplicity of pure strategy equilibria exist when the auction is uniform, but not when it is discriminatory (figure 14). Moreover, due to the asymmetry in production costs, the pure strategy equilibria are asymmetric.

Proof. When the realization of demands $\left(\theta_{j}, \theta_{i}\right)$ is low (area $A$ ), both suppliers have enough capacity to satisfy total demand and the equilibrium is the typical Bertrand equilibrium with asymmetries in costs where the efficient supplier submits a bid equal to the marginal cost of the inefficient one to extract the efficiency rent. 
When the realization of demands $\left(\theta_{j}, \theta_{i}\right)$ is intermediate (area $A 1$ ) at least one of the suppliers faces a positive residual demand. When the generation costs are high, the efficient supplier prefers to submit a low bid to extract the efficiency rents. In such a case, multiplicity of pure strategies equilibria exist for both type of auctions where the inefficient supplier submits the maximum bid allowed by the auctioneer and the efficient supplier submits a bid that made undercut unprofitable. When the generation costs are low, the efficiency rents are very low and the efficient supplier prefers ot satisfy the residual demand, in such a case it submits the maximum bid allowed by the auctioneer. Therefore, as in lemma three, multiplicity of equilibria exist when the auction is uniform, but not when it is discriminatory.

When the realization of demands $\left(\theta_{j}, \theta_{i}\right)$ is high (area $B$ ) both suppliers have incentives to submit a high bid and satisfy the residual demand. In such a case, multiplicity of equilibria exist when the auction is uniform, but not when it is discriminatory

When the realization of demands $\left(\theta_{j}, \theta_{i}\right)$ is intermediate or high and the auction is discriminatory, a pure strategy equilibrium does not exist. However, the model satisfies the properties established by Dasgupta and Maskin (1986) which guarantee that a mixed strategy equilibrium exists.

Lemma 6. In the presence of transmission constraints and positive transmission costs. In a mixed strategy equilibrium, no supplier submits a bid lower than bid $\left(\underline{b}_{i}\right)$ such that

$$
\left(\underline{b}_{i}-c_{i}\right) \min \left\{\theta_{i}+\theta_{j}, k\right\}=\left(P-c_{i}\right) \max \left\{0, \theta_{i}+\theta_{j}-k\right\} .
$$

Moreover, the support for the mixed strategy equilibrium for both suppliers is $S=$ $\left[\max \left\{\underline{b}_{i}, \underline{b}_{j}\right\}, P\right]$.

Proof. The proof proceeds as in lemma two.

Using lemmas five and six, I characterize the equilibrium.

Proposition 4. When the suppliers are asymmetric in generation capacity and generation costs, the characterization of the equilibrium falls into one of the next three categories.

i Low demand (area $A$ ). The equilibrium strategy pair is in pure strategies for both types of auctions.

ii Intermediate demand (area $A 1$ ). When the production costs are high, the equilibrium strategy pair is in pure strategies for both types of auctions. By the contrary, when the production costs are low, the equilibrium strategy pair is in pure strategies when the auction is uniform and in mixed strategies when it is discriminatory.

iii High demand (area $B$ ). The equilibrium strategy pair is in pure strategies when the auction is uniform and in mixed strategies when it is discriminatory.

Proof. The proof proceeds as in proposition two.

As in the presence of transmission constraints and transmission costs. The main differences between both type of auctions are when the realization of demand is intermediate 
Figure 14: Equilibrium areas. Asymmetries in generation capacity and production costs.
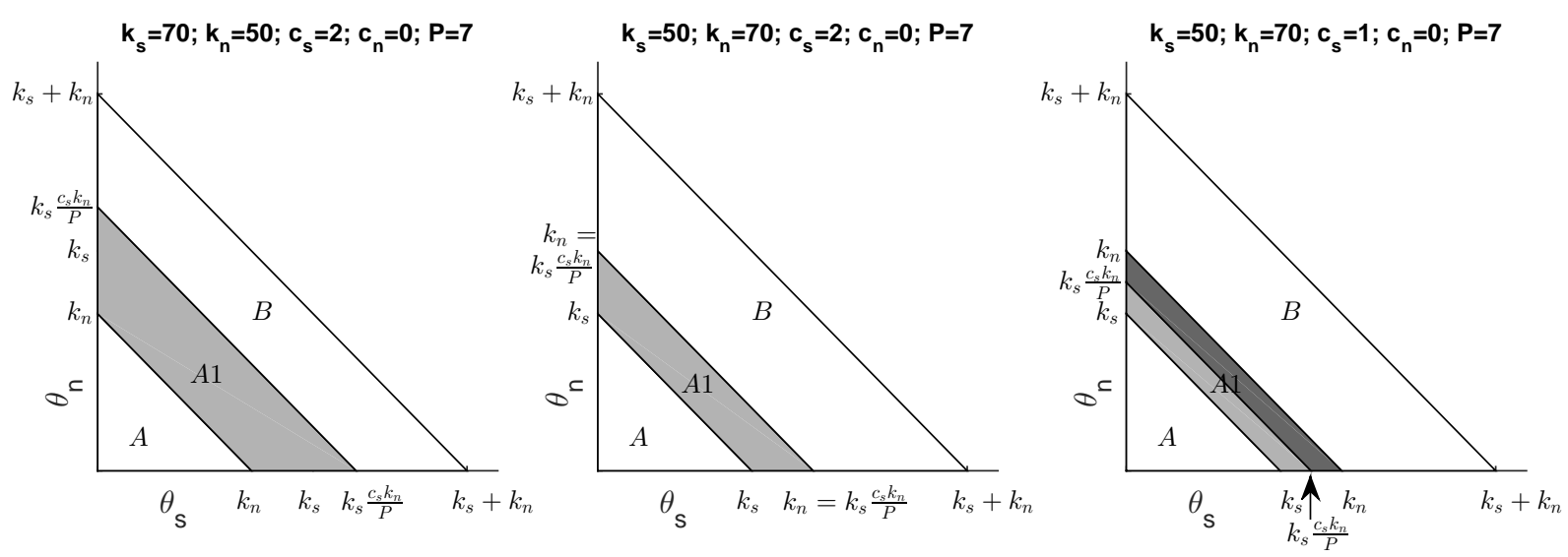

(area $A 1$ ). In that case, when the production costs are high, it is profitable for the efficient supplier to undercut the inefficient one to extract the efficiency rent and the equilibrium pair strategies is in pure strategies for both type of auctions. By the contrary, when the production costs are low, the efficient supplier prefers to submit a high bid and satisfy the residual demand. In such a case, multiplicity of pure strategies equilibria exist where the efficient supplier submits the maximum bid allowed by the auctioneer and the inefficient one submits a bid that make undercut unprofitable. When the auction is discriminatory, the equilibrium is in mixed strategies. Hence, when the production costs are low, the discriminatory price auction performs better in terms of equilibrium price and electricity production cost minimization.

Figure 14 presents a summary of the results presented in proposition four when the realization of demand belongs to area $A 1$ for different parameter specifications. The left panel of the figure shows the characterization of the equilibrium when the smaller supplier is also the most efficient. In that case, when the auction is uniform, multiplicity of equilibria exists where the inefficient supplier submits the maximum price allowed by the auctioneer; by the contrary, when the auction is discriminatory the equilibrium is in mixed strategies and the inefficient supplier can be dispatched first with positive probability. Therefore, the uniform price auction performs better in terms of efficiency, but worse in terms of prices. The central panel shows the equilibrium areas when the larger supplier is the most efficient one and the production costs are high. In that case the efficient supplier undercut the inefficient one and the equilibrium is the same for both types of auctions. The panel in the right presents the equilibrium areas when the production costs are low. In that case, a new area appear (black grey area). When the auction is uniform the efficient supplier faces a high residual demand and prefers to submit a high bid. Hence when the larger supplier is also the efficient one and the difference in costs is low, the uniform price auction performs worse in terms of efficiency and equilibrium prices.

The main results presented in proposition four depend crucially on the value of the production cost (low or high). Due to the importance that the production cost has on the results of the model, I analyze the effect that an increase in production costs has on equilibrium market outcomes. 
Proposition 5. Increase in production costs when the realization of demands $\left(\theta_{j}, \theta_{i}\right)$ belong to area $A 1$.

- When the production costs are low, an increase in costs doesn't modify the equilibrium price when the auction is uniform, but reduces it when the auction is discriminatory (an increase in production costs is pro-competitive).

- When the production costs are high, an increase in those costs increases the equilibrium price for both types of auctions (an increase in production costs is anticompetitive).

Proof. The proof proceeds as in proposition three. 


\section{References}

Andersson, O., Argenton C. and Weibull, J., 2014, "Robustness to Strategic Uncertainty", Games and Economic Behavior, 85, 272-288.

Blázquez, M., 2015, "Transmission Costs, Transmission Capacities and their Influence on Market Power in Wholesale Electricity Markets", IFN working paper no. 1070.

Borenstein, S., Bushnell J. and Stoft S., 2000, "The Competitive effects of transmission capacity in a deregulated electricity industry," Rand Journal of Economics, 31 (2), 294325 .

Brezis, E. Krugman P. R. and Tsiddon, D. (1993) "Leapfrogging in International Competition: A Theory of Cycles in National Technological Leadership," American Economic Review, 83, 1211-219.

Cabrales, A., Gracía-Fontes W. and Motta M. (2000) "Risk Dominance Selects the leader: An Experimental Analysis" International Journal of Industrial Organization, 18, 137-162.

Dasgupta, P., Maskin E., 1986, "The Existence of Equilibrium in Discontinuous Economic Games, II: Applications," The Review of Economic Studies, 53 (1), 27-41.

Deneckere, R. and Kovenock, D., 1996, "Bertrand-Edgeworth Duopoly with Unit Cost Asymmetry," Economic Theory, 8, 1-25.

Dixon H., (1984) "The existence of mixed-strategy equilibria in a price-setting oligopoly with convex costs," Economics Letters, Vol. 16, 205-212.

Downward, A., Philpott, A. and Ruddell K., 2014, "Supply Function Equilibrium with Taxed Benefits," Working paper.

ENTSO-E, 2013, "ENTSO-E ITC Transit Losses Data Report".

ENTSO-E, 2014, "ENTSO-E ITC Overview of Transmission Tariffs in Europe: Synthesis $2014 "$.

Escobar, J.F., and Jofré A., 2010, "Monopolistic Competition in Electricity Networks with Resistance Losses," Economic Theory, 44, 101-121.

Fabra, N., von der Fehr N. H. and Harbord D., 2006, "Designing Electricity Auctions," Rand Journal of Economics, 37 (1), 23-46.

Fabra, N. and Reguant, M., 2014, "Pass-Through of Emissions Costs in Electricity Markets," American Economic Review, 104 (9), 2872-2899.

Flamm, H. and Helpman E. (1987) "Vertical Product Differentiation and North-South Trade," American Economic Review, 77, 810-822. 
Holmberg, P. and Philpott A.B., 2012, "Supply Function Equilibria in Transportation Networks," IFN Working Paper 945.

Hu, S., Kapuscinski R. and Lovejoy W. S., (2010) "Bertrand-Edgeworth Auction with Multiple Asymmetric Bidders: The Case with Demand Elasticity" SSRN Working Paper.

Janssen, M. C. W., and Moraga-González J. L., (2004) "Strategic Pricing, Consumer Search and the Number of Firms," Review of Economic Studies, Vol. 71, 1089-1118.

Karlin S., (1959) "Mathematical Methods and Theory in Games, Programming and Economic," Vol. II (London: Pergamon Press).

Kreps D. M., and Scheinkman J. A., (1984) "Quantity Precommitment and Bertrand Competition Yield Cournot Outcomes," RAND Journal of Economics, Vol. 14, 326-337.

Krugman, P. (1980) "Scale Economies, Product Differentiation, and the Pattern of Trade," American Economic Review, 70, 950-959.

Marion, J. and Muehlegger, E., 2011, "Fuel Tax Incidence and Supply Conditions," Journal of Public Economics, 95 (9-10), 1202-12.

McKelvey, R., and Palfrey, T. R., (1998) "Quantal Response Equilibria for Normal Form Games" Games and Economic Behavior, 10, 6-38.

Osborne, M. and Pitchik, C., 1986, "Price Competition in a capacity-constrained duopoly," Journal of Economic Theory, 38, 283-260.

Rosenthal, R.W., (1980) "A Model in which an Increase in the Number of Sellers Leads to a Higher Price" Econometrica, Vol. 48, No. 6, 1575-1579.

Shapley L. S., (1957) "A Duopoly Model with Price Competition," Econometrica, Vol. 25, 354-355.

Shilony Y., (1977) "Mixed Pricing in Oligopoly," Journal of Economic Theory, Vol. 14, 373-388.

Shitovitz, B., 1973, "Oligopoly in Markets with Continuum of Traders," Econometrica, 41, 467-501.

Svenska Kraftnät, 2012, "Transmission Tariff" http://www.svk.se/Start/English/Operationssand-market/Transmission-tariff/.

Varian, H., 1980, "A Model of Sales," American Economic Review, 70, 651-659.

von der Fehr, N.H. and Harbord D., 1993, "Spot Market Competition in the UK Eletricity Industry," Economic Journal, 103(418), 531-46. 